\title{
Le sanctuaire gallo-romain de La Pièce des Côtelets à Saint-Martin-des-Entrées (Calvados)
}

The Roman Sanctuary of La Pièce des Côtelets at Saint-Martin-des-Entrées (Calvados)

Das gallo-römische Heiligtum von „La Pièce des Côtelets“ bei Saint-Martin-desEntrées (Calvados)

El santuario galo-romano de "La Pièce des Côtelets" en Saint-Martin-des-Entrées (Calvados)

\section{Laurent Paez-Rezende et Yves-Marie Adrian}

\section{OpenEdition}

\section{Journals}

Édition électronique

URL : https://journals.openedition.org/rao/2588

DOI : $10.4000 /$ rao. 2588

ISBN : 978-2-7535-4053-8

ISSN : $1775-3732$

\section{Éditeur}

Presses universitaires de Rennes

\section{Édition imprimée}

Date de publication : 15 décembre 2014

Pagination : 251-287

ISBN : 978-2-7535-4051-4

ISSN : 0767-709X

Référence électronique

Laurent Paez-Rezende et Yves-Marie Adrian, « Le sanctuaire gallo-romain de La Pièce des Côtelets à Saint-Martin-des-Entrées (Calvados) », Revue archéologique de l'Ouest [En ligne], 31 | 2014, mis en ligne le 15 décembre 2016, consulté le 22 août 2022. URL : http://journals.openedition.org/rao/2588 ; DOI : https://doi.org/10.4000/rao.2588 


\title{
Le sanctuaire gallo-romain de La Pièce des Côtelets à Saint-Martin-des-Entrées (Calvados)
}

\author{
The Roman Sanctuary of La Pièce des Côtelets at Saint-Martin-des-Entrées (Calvados)
}

\author{
Laurent PAEZ-Rezende* et Yves-Marie Adrian**
}

\begin{abstract}
Bayeux, chef-lieu antique de la cité des Baïocasses, le sanctuaire de La Pièce des Côtelets à Saint-Martin-des-Entrées inclut au centre d'un péribole de 4500 mètres carrés, compartimenté et délimité au moyen de larges fossés, un temple à galerie avec cella centrale, un édicule et une vaste bâtisse sur ossature de bois. Cet ensemble religieux est intégré dans un parcellaire au quadrillage dense et sans doute associé à un établissement rural dont le cœur n’a pas été repéré. Il s'accompagne de nombreux dépôts de mobilier, céramiques et restes de faune principalement, recueillis dans des fossés ou des fosses et dont le caractère rituel ou votif ne fait pas de doute. Cependant, les faciès céramiques ne montrent pas de grandes originalités en comparaison des corpus provenant des sites d'habitats régionaux. Construit vers le milieu du I ${ }^{\mathrm{er}} \mathrm{s}$. apr. J.-C., le sanctuaire s’agrandit au début du $\mathrm{II}^{\mathrm{e}}$ siècle, période qui marque l'apogée de son fonctionnement jusqu’à la fin du II ${ }^{\mathrm{e}}$ siècle, qui correspond à son abandon.
\end{abstract}

\begin{abstract}
The La Pièce des Côtelets sanctuary at Saint-Martin-des-Entrées, located at about 4,5 km from Bayeux, the major city of Baïocasses tribe, includes a $4500 \mathrm{~m}^{2}$ compartmented peribol at its centre, limited by large ditches, a temple with a central cella and gallery, an aedicule and a vast wooden structured building. This religious establishment is integrated into a quadrangular enclosure probably linked to an important rural settlement the heart of which has yet to be discovered. The site has provided many deposits, pottery and animal bone principally, found in the ditches or in votive pits. However, the pottery shows no originality in relation to the assemblages from regional settlement sites. Built around the middle of the 1st century AD, the sanctuary was extended at the beginning of the 2nd century, period which marks the zenith of its use until the end of the 2nd century when the site was abandoned.
\end{abstract}

Mots clés : sanctuaire, péribole, temple, céramiques, dépôt cultuel, parcellaire.

Keywords: sanctuary, peribol, temple, pottery, ritual deposit, enclosure.

\section{LOCALISATION}

À $4,3 \mathrm{~km}$ au sud-est du centre antique de Bayeux (Augustodurum), chef-lieu de la cité des Baïocasses (province Lyonnaise), le sanctuaire se positionne sur les plateaux de la frange orientale de la civitas, ici séparée de celle des Viducasses par la vallée de la Seulles, distante d'environ $1,8 \mathrm{~km}$ du site (fig. 1).

* Inrap-Basse-Normandie, 4 boulevard de l'Europe - 14540 BOURGUÉBUS.

** Inrap-Haute-Normandie, immeuble Mermoz, 30 boulevard de Verdun - 76120 GRAND-QUÉVILLY.

\section{Le contexte d'étude}

Les vestiges ont été reconnus, en 1996, dans le cadre d'un diagnostic archéologique mené sur le contournement autoroutier sud-ouest (RN13) de l'agglomération de Bayeux. Entre juillet et novembre 2000, une fouille préventive partielle a été conduite sous la forme d'ouvertures en grandes fenêtres et en tranchées supplémentaires. Ce dispositif a permis d'explorer, sur 20000 mètres carrés, une partie du sanctuaire (3500 mètres carrés de surface ouverte) et les marges d'un établissement rural contigu, tout en ne permettant pas la perception complète du sanctuaire. 


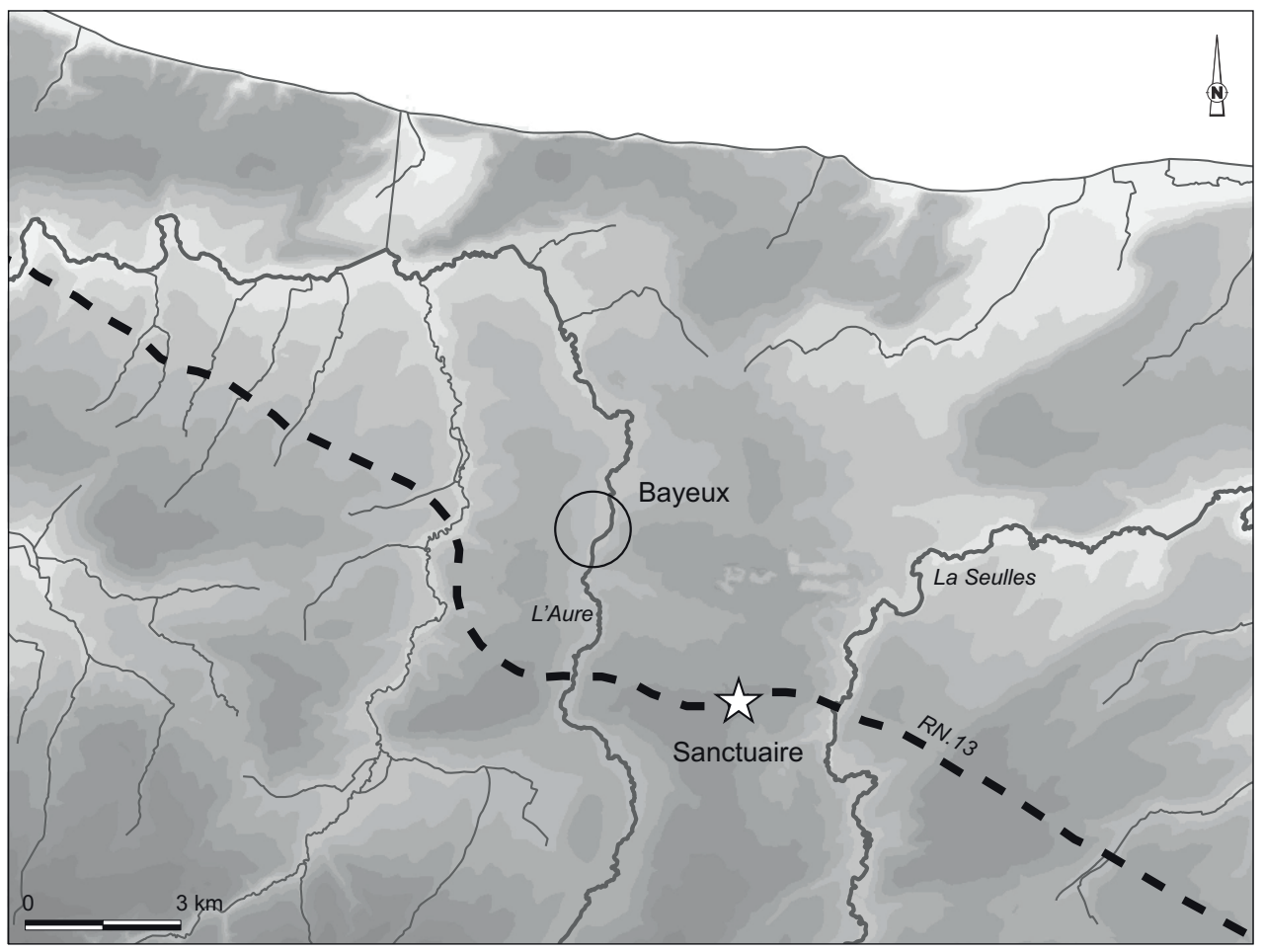

Figure 1 : Saint-Martindes-Entrées : localisation du sanctuaire de "La Pièce des Côtelets".

Figure 1: Saint-Martin-desEntrées: location of the sanctuary "La Pièce des Côtelets".
Déjà très engagé dans le Bessin, ce secteur constitue malgré tout une zone de contact avec les confins nord-ouest de la plaine de Caen où, dans un paysage encore très ouvert, prédominent les grandes cultures. Le sanctuaire s'implante plus particulièrement sur l'une des éminences d'un plateau très peu mouvementé qui culmine à 75 m NGF. Ce dernier est délimité, à l'est, par la vallée de la Seulles (30 m NGF) et, à l'ouest, par celle de l'Aure ( 45 m NGF). Sur l'emprise, l'assiette des terrains est globalement plane, mais les vestiges sont plus précisément positionnés en léger retrait de la tête d'un petit thalweg, situé à la rupture sud-orientale de l'éminence d'où s'écoulent deux résurgences alimentant l'un des nombreux affluents de la Seulles.

Sur le plan géologique, le substratum calcaire du Bathonien inférieur (Jurassique) est recouvert par des lœss weichséliens avec, au sommet, des placages limono-argileux bruns orangés, pouvant être très épais et dépasser les deux mètres. L'existence de carrières antiques à environ deux kilomètres plus à l'est et les fosses d'extraction sur le site attestent d'une exploitation de ces deux principales matières premières aisément accessibles.

La seule stratigraphie directement liée à l'occupation antique est un niveau limoneux gris avec mobilier, préservé dans une convexité du terrain au centre du sanctuaire. Les vestiges sont en effet partout arasés jusqu'au sommet des fondations, souvent profondes, et sont marqués par une récupération accrue des matériaux. La plupart des maçon- neries ont été démontées jusqu'au fond des fondations et leur tracé affleure en général à la base de la terre végétale. Cet état de conservation n'a pas permis de dresser un diagramme stratigraphique satisfaisant. L'organisation, l'évolution et la mise en phase du site reposent donc principalement sur les quelques recoupements de vestiges et le mobilier, notamment céramique, abondant et relativement bien réparti.

\section{Le sanctuaire dans son environnement antique} (fig. 2)

Dans ce secteur, deux voies, l'une attestée et l'autre supposée, semblent encadrer le site. La première, située à un kilomètre au nord-est relie Bayeux à Caen en reprenant, peu ou proue, le tracé de la RN13 entre les deux agglomérations. L'authenticité de cette voie a longtemps été controversée et les fouilles menées en 1997, sur l'échangeur de "La Corneille » à Bretteville-l'Orgueilleuse, en rive nord de son tracé, n'ont pas permis de trancher sur la question. Elle a depuis été validée par des interventions réalisées à Canchy (Ferette, 2004) et à Loucelles (Giazzon, 2011). La seconde constituerait l'axe direct menant de Bayeux à Vieux (Araegenua - Viducasses) passant à moins d'1 km à l'ouest du site en direction de Tilly-sur-Seulles. Enfin, il faut mentionner, bien plus au nord, un itinéraire dit " côtier " ou " littoral ", filant vers l'est, en direction de Reviers et Douvres-la-Délivrande. Bien qu'il n’ait pas fait l'objet de 


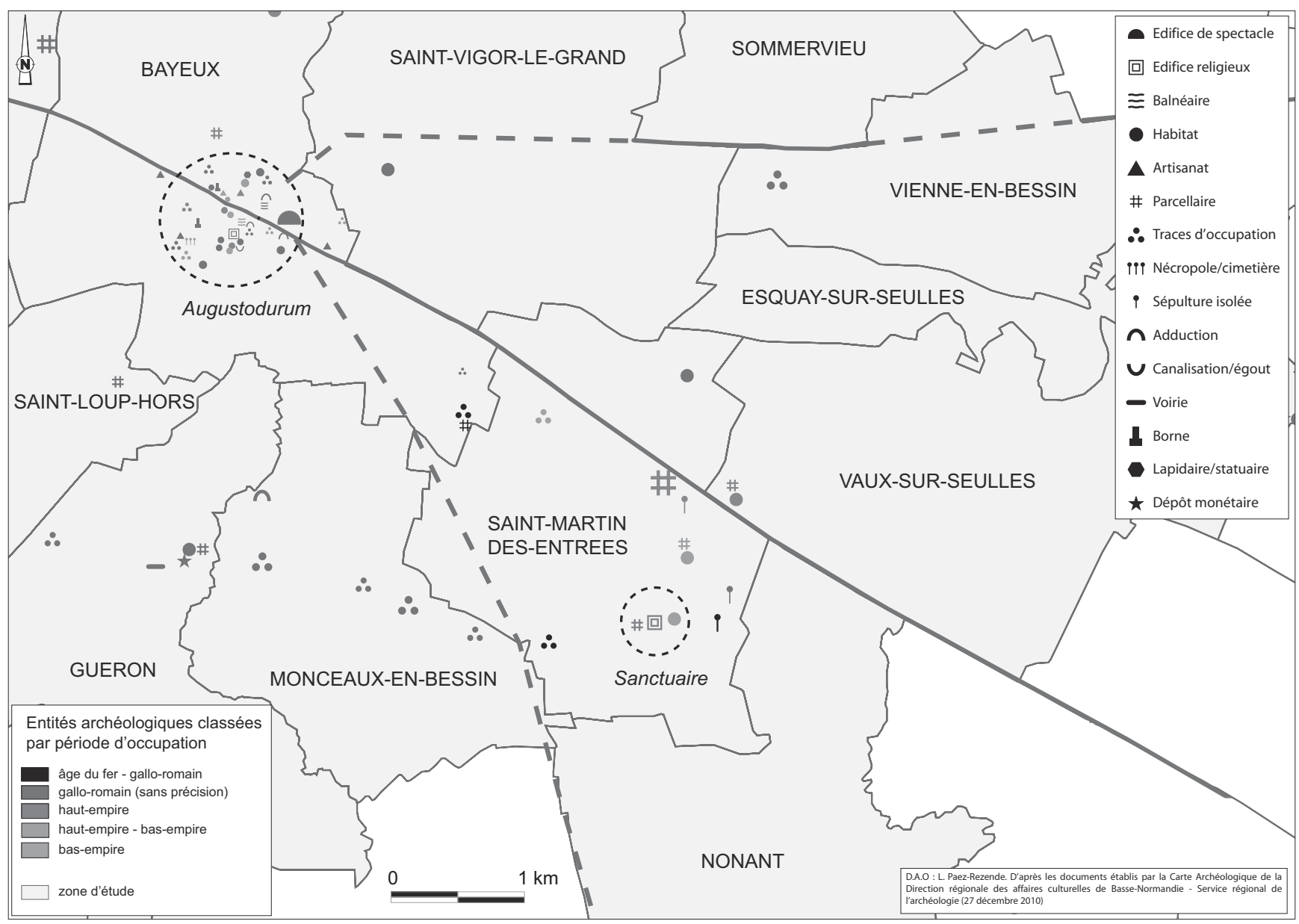

Figure 2 : (Voir planche couleur) Les sites antiques autour de Bayeux (Augustodurum) et du sanctuaire de Saint-Martin-des-Entrées. Figure 2: (See colour plate) The Roman sites around Bayeux (Augustodurum) and the sactuary of Saint-Martin-des-Entrées.

sondages, il semble justifié par le recoupement des études anciennes (Dorlando, 1940 et Musset, 1947), des données de la prospection aérienne (G. San Juan et J. Desloges), montrant une distribution des sites protohistoriques et antiques le long de son parcours, et la découverte, en 1819, d'une borne milliaire dans la commune du Manoir (Lambert, 1841), le long de la RD12 qui se superposerait en partie à cet axe ancien.

Aux abords du sanctuaire, la plupart des sites recensés évoque la gestion et la mise en valeur de l'espace rural. Il s'agit principalement d'éléments de parcellaires et d'indices d'habitat, montrant plusieurs noyaux d'occupation encadrés par des réseaux de fossés dont les orientations semblent s'appuyer sur le tracé des voies antiques reconnues ou hypothétiques.

Le bilan est bien renseigné pour la période gallo-romaine et révèle une occupation dense et structurée, mais principalement à caractère rural ou agraire. Cette densité est certainement le reflet de l'influence et de la dynamique que devait exercer le chef-lieu sur sa proche "banlieue ».
Le sanctuaire de la Pièce de Côtelets est le seul établissement religieux répertorié dans cet espace. Aux portes de la ville antique d'Augustodurum, il s'intègre et évolue à l'intérieur d'un réseau parcellaire globalement positionné sur les orientations cardinales et au contact d'un établissement rural (fig. 3), dont la chronologie s'étire entre le milieu du Ir siècle et la première moitié du $\mathrm{III}^{\mathrm{e}}$ siècle. Ce dernier, dont la nature précise nous échappe, est probablement situé à l'extérieur nord-est de l'emprise, près d'un secteur riche en débris de démolition (moellons, mortier, terres cuites architecturales) et en rejets d'occupation (céramiques, faunes, charbons de bois, etc.). À moins de 100 mètres au-dessus de la limite septentrionale du sanctuaire, au moins trois bâtiments, composés de six, neuf ou onze poteaux, constituent certainement des annexes agricoles au cœur de l'espace parcellisé dans lequel est également établie le péribole fossoyé du sanctuaire. 


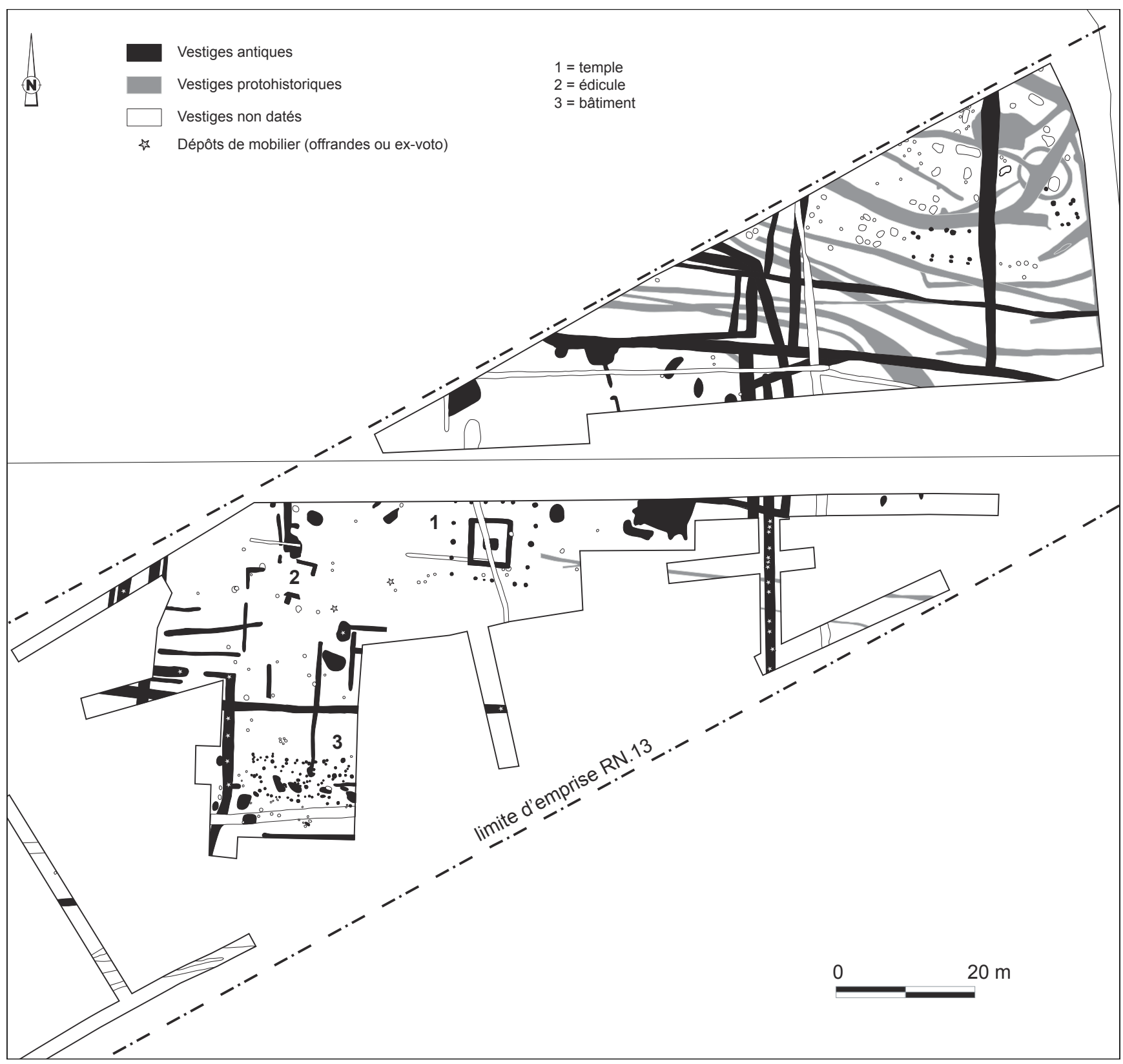

Figure 3 : Saint-Martin-des-Entrées : plan masse des vestiges.

Figure 3: Saint-Martin-des-Entrées: site plan.

\section{DesCription DU SANCTUAIRE}

Toutes phases confondues, le sanctuaire occupe une surface maximum de 5000 mètres carrés (fig. 4). L'aire sacrée de plan rectangulaire est délimitée par de larges fossés et subdivisée par des segments plus restreints et non jointifs. Un temple à cella maçonnée pourvue d'une galerie sur poteaux occupe une position centrale dans le sanctuaire. Un édicule (?), deux bâtisses sur poteaux, des fosses et des trous de poteau complètent le panorama des équipements cultuels.
Quelques offrandes ont été déposées à même le sol, mais la plupart sont placées dans les fossés.

\section{Le péribole (fig. 5)}

Défini au moyen de fossés s'articulant avec le parcellaire antique du secteur, il présente deux états. Généralement, ce type de clôture est utilisé lors de l'implantation précoce des sanctuaires et est très vite remplacé par une maçonnerie (Fauduet, 1993b, p. 104-105 et 2010, p. 73-75; 


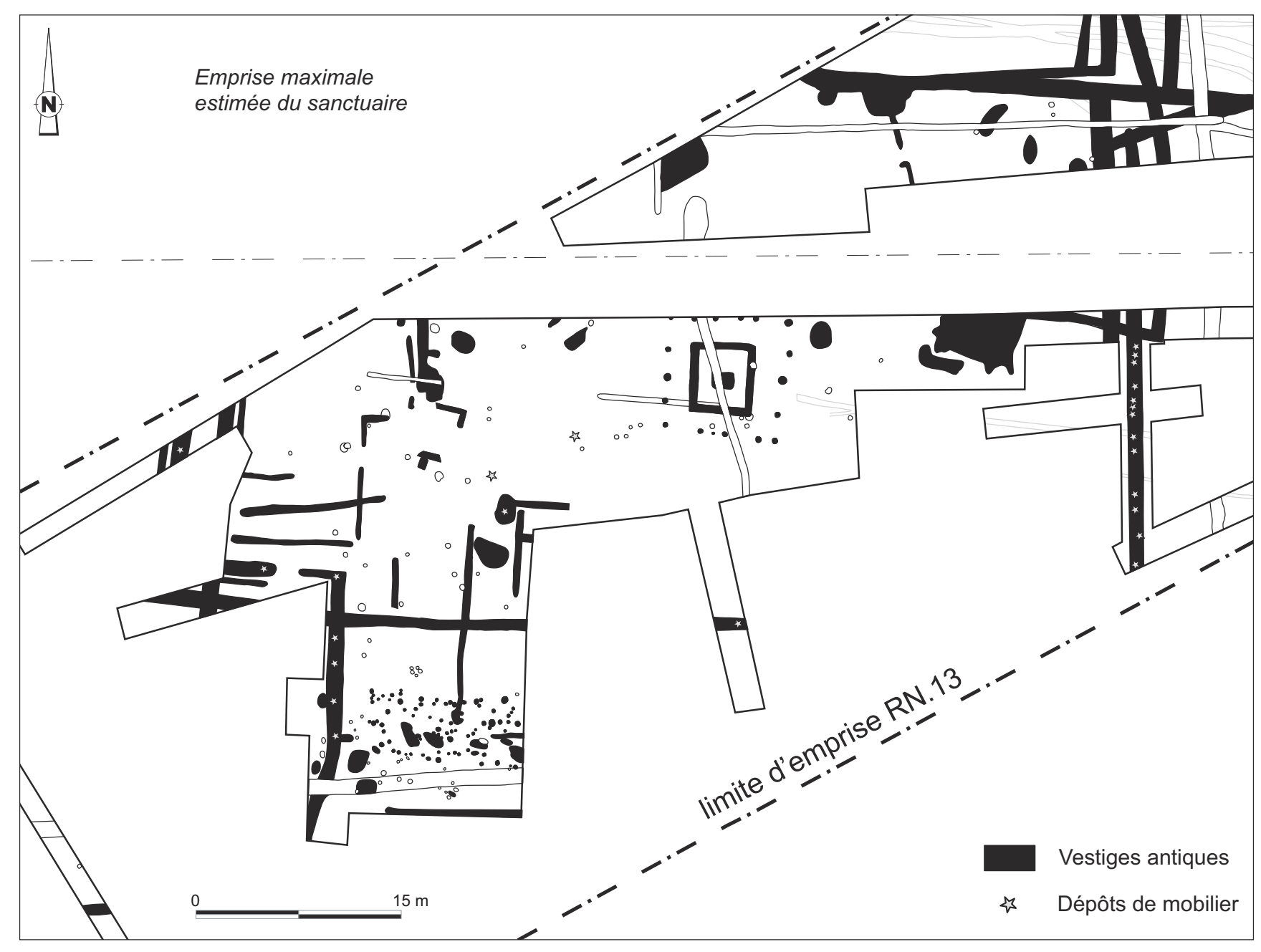

Figure 4 : Saint-Martin-des-Entrées : détail de l'emprise du sanctuaire au sein des vestiges de la période antique.

Figure 4: Saint-Martin-des-Entrées: detail of the sanctuary in relation to the Roman remains.

Van Andringa, 2002, p. 95 et 108-109). Ce n'est pas le cas ici, où il est maintenu même dans la phase d'agrandissement. La présence d'un talus soulignant et renforçant les limites de l'aire sacrée est envisagée, sans pour autant être confirmée par les coupes pratiquées dans les fossés périmétriques.

\section{Le péribole 1}

Le premier état du péribole prend donc la forme d'un enclos fossoyé rectangulaire (St. 83, 1023, 1070 et 1086) de 77,50 par 57,50 mètres, soit une surface d'à peine 4500 mètres carrés. D'orientation principale est-ouest, il s'inscrit parfaitement dans l'organisation générale du parcellaire limitrophe et la plupart des fossés ainsi employés voient leur tracé se prolonger bien au-delà des limites de l'enclos cultuel. Ces limitent possèdent des dimensions similaires, soit des largeurs avoisinant les 1,50 mètre pour des profondeurs rarement supérieures à 0,80 mètre. Les profils sont généralement en « $V$ » et ont tous reçu un même comblement détritique d'origine anthropique (fig. 6). Parmi les rejets, les fragments de céramiques situent leur comblement dans le courant de la seconde moitié du I $^{\text {er }}$ siècle, voire au début du II ${ }^{\mathrm{e}}$ siècle.

La seule entrée connue est située dans l'angle nord-est, où elle est matérialisée par une interruption dans le tracé du fossé 1023.

\section{Le péribole 2}

L'agrandissement de l'aire sacrée et la modification de sa configuration initiale se manifestent par la création de nouveaux fossés de délimitation. Si les fossés St. 80, 1022, 1071 et 1230 sont très proches des anciens axes, voire les chevauchent, les fosses 1054 et 1214 entraînent en revanche une extension de 15 mètres de l'aire sacrée sur les trois quarts de sa façade méridionale, soit une surface supplémentaire d'environ 1100 mètres carrés. Cela représente un agrandis- 


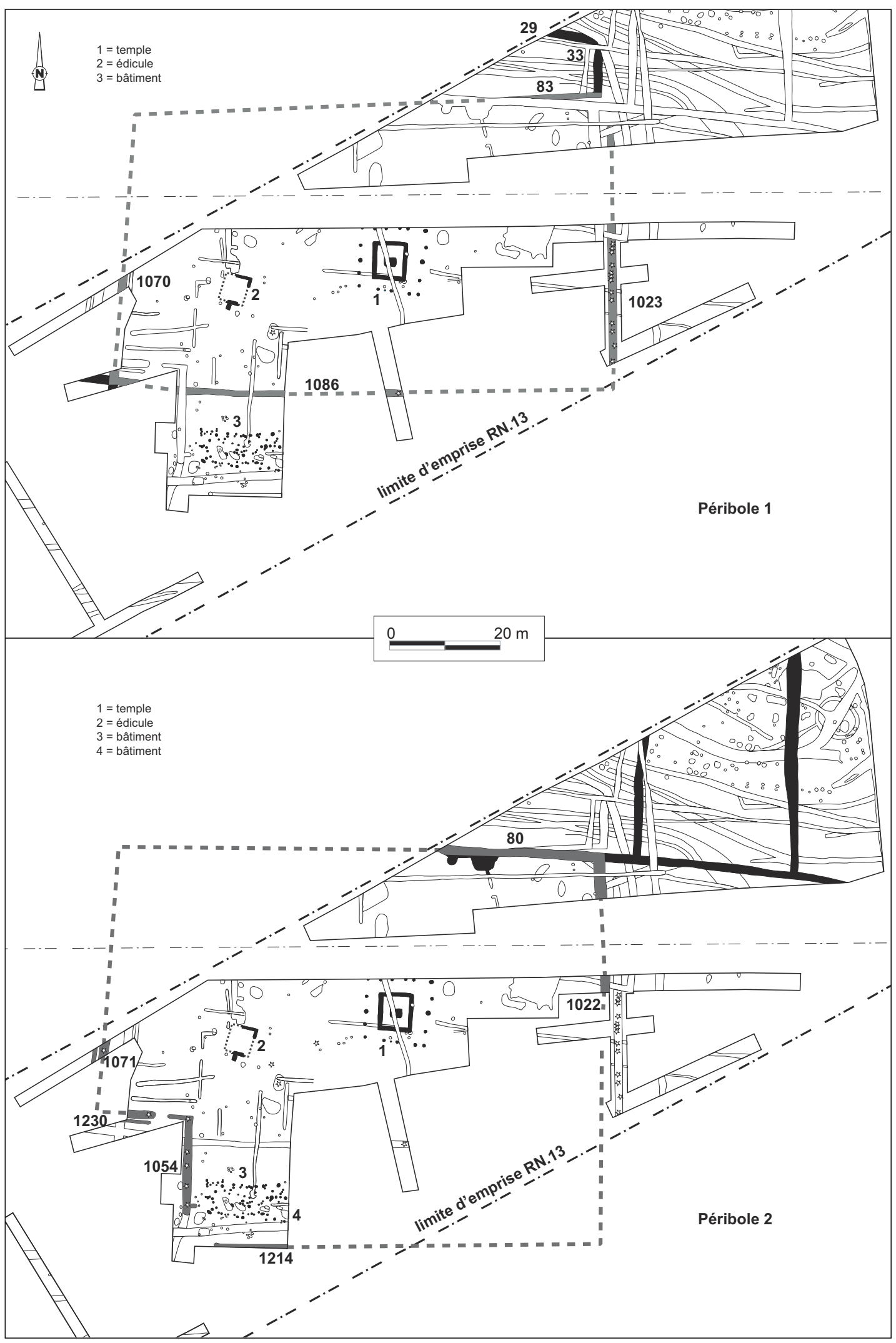

Figure 5 : Saint-Martin-des-Entrées : configuration des deux périboles du sanctuaire. Figure 5: Saint-Martin-des-Entrées: configuration of the site's two peribols. 


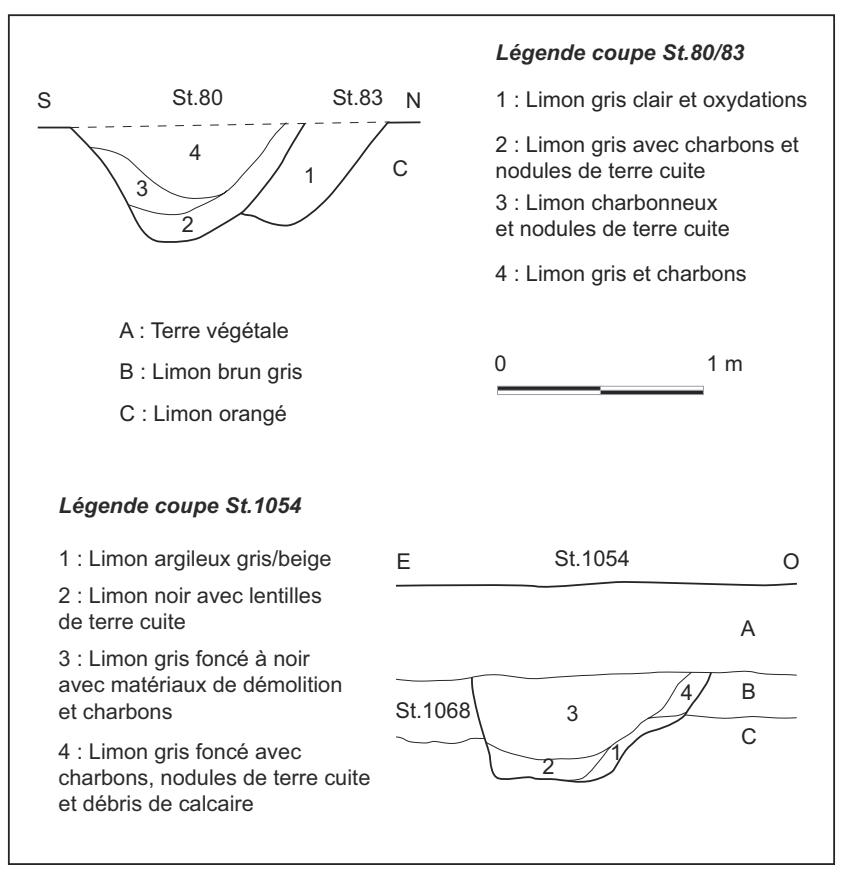

Figure 6 : Saint-Martin-des-Entrées : morphologie et stratigraphie des fossés des deux périboles.

Figure 6: Saint-Martin-des-Entrées: morphology and stratigraphy of the peribol ditches.

sement de $25 \%$, en comparaison de l'espace initial, pour atteindre une surface circonscrite très comparable à celle de certains sanctuaires suburbains tel que celui de Jublains en Mayenne (5694 $\mathrm{m}^{2}$; Naveau, 1997, p. 118) D'un point de vue morphologique, les nouveaux fossés sont semblables à ceux de la première phase, mais avec des comblements détritiques bien plus marqués (fig. 6).

Au moins deux entrées sont dorénavant attestées, l'une de 7,50 mètres de large marquée par l'interruption des fossés 1054 et 1214 dans l'angle sud-ouest, soit à l'opposé de l'entrée utilisée dans la phase précédente, et l'autre de 2 mètres sur l'axe du fossé 1230 , qui assure la relation entre les fossés 1054 et 1071. Une troisième entrée est supposée sur la façade orientale de l'enceinte, à peu près à mi-distance de sa largeur, où l'absence du fossé (St. 1022) dans une tranchée de repérage complémentaire paraît significative.

La position excentrée des entrées sur les deux phases d'aménagement du péribole n'est pas si rare dans les sanctuaires (Fauduet, 2010, p. 76), bien que souvent moins prononcée. Mais en dehors de Corseul, aucun exemple ne mentionne une entrée localisée dans un angle. Ce constat soulève des interrogations puisqu'une telle configuration déroge au principe même d'axialité qui prévaut dans la plupart des schémas rencontrés. Ces derniers sont notamment illustrés par l'édifice des Hernies à Macé (Orne), où l'entrée excentrée sur la façade orientale du sanctuaire est toutefois positionnée dans l'axe du temple, des Perrières et surtout de La Foresterie à Allonnes (Sarthe; Gruel et Brouquier-Reddé, 2003 , p. 25 et 55), un modèle d'axialité à l'instar de celui de Cherré à Aubigné-Racan (Sarthe), pour ne citer que les références du grand quart nord-ouest de la Gaule romaine.

À la différence de Macé ou d'Allonnes La Foresterie, aucune structure ne vient, ici, suggérer l'existence d'un porche d'entrée. Aucun trou de poteau n'est à signaler dans l'environnement direct des interruptions de l'enceinte et, malgré un recoupement postérieur, l'extrémité du fosse 1023 ne montre pas d'empreinte désignant l'emplacement d'un élément dédié à cette fonction. En conséquence, cette entrée semble exempte de système de fermeture, suggérant un libre accès à l'aire cultuelle.

\section{La cour (fig. 7)}

Aucun indice d'un quelconque revêtement n'est attesté à l'intérieur de l'aire sacrée et la pédogenèse, qui s'y trouve préservée à la faveur d'une légère convexité naturelle dans les placages limoneux, milite pour des activités se déroulant à même le sol naturel. Cet horizon limono-argileux gris à noir, d'une vingtaine de centimètres d'épaisseur, positionné juste sous la terre végétale, nappe l'intérieur de l'aire sacrée et englobe la plupart des édifices et aménagements en lien avec l'activité du sanctuaire. Il renferme de nombreux fragments de céramique, d'ossements de faune, des clous et deux fonds de vases assimilés à des offrandes. Cette couche semble s'être constituée pendant toute la durée de fonctionnement du sanctuaire.

Dès l'origine, cet espace a fait l'objet d'un cloisonnement au moyen d'un réseau de fins segments de fossés, assez dense et respectant les orientations générales. Ils sont uniquement implantés dans la partie occidentale de l'aire cultuelle et respectent les axes fixés par les fossés d'enceinte avec lesquels ils n'ont d'ailleurs jamais de contacts. Les coupes montrent des profils en « $U$ » et des fonds uniformes ne laissant apparaître aucune trace de pieux, ce qui n'exclut par pour autant l'insertion d'éléments de palissades dans les tranchées, voire de plantations à vocation de plesses. Manifestement, ils s'imposent comme l'une des spécificités du site, dont l'organisation en plan n'a rien de commun avec les traditionnelles subdivisions parcellaires, mais contribue à délimiter des espaces plus ou moins exigus et communiquant entre eux. À l'évidence, ces tracés semblent voués à matérialiser des partitions discontinues, dont la signification fonctionnelle ou symbolique reste à définir, surtout quand ils sont positionnés en barrage des entrées ou en doublons des fossés du péribole. Les quelques fosses et trous de poteau présents dans ce secteur ne permettent pas de restituer des espaces enclos s'appuyant sur ces éléments de partition. L'idée de 


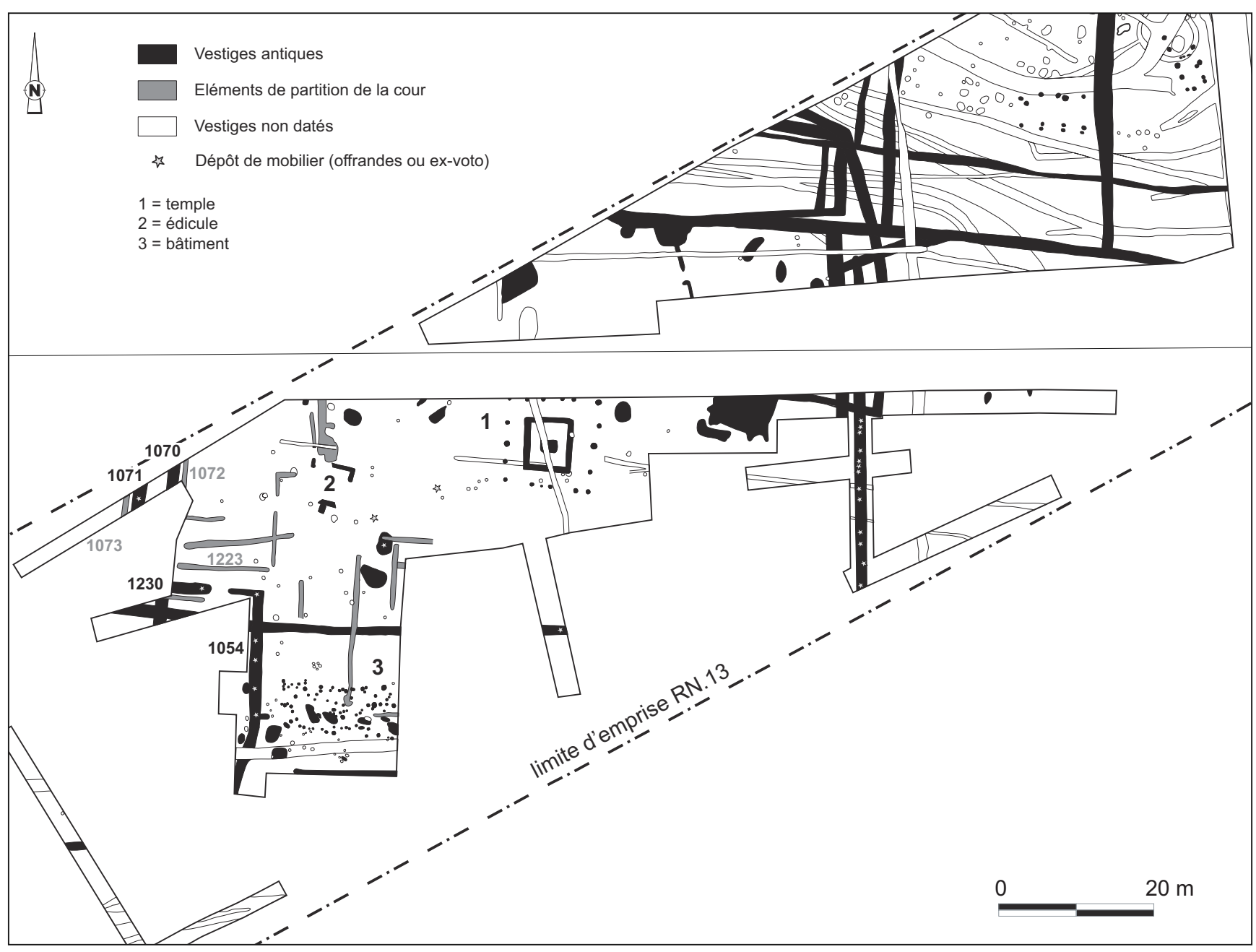

Figure 7 : Saint-Martin-des-Entrées : la cour et ses aménagements. Figure 7: Saint-Martin-des-Entrées: the courtyard and its structures.

haies arbustives agrémentant l'aire sacrée ne résiste pas à la réalité d'un remplissage trop hydromorphe, pas plus que des palissades. Leur création dans l'optique d'un drainage des eaux de ruissellement n'est pas davantage convaincante au regard de leur segmentation et de leur déconnexion vis-à-vis des fossés périmétriques, comme d'ailleurs des plus grandes fosses du secteur.

De tels assemblages peuvent apparaître assez atypiques et vont dans le sens d'une relation directe avec la nature religieuse des lieux : figuration d'un parcours processionnel, protection symbolique, découpage des espaces de service, etc.

\section{Le temple (fig. 8)}

Il s'agit d'un édifice d'une surface d'environ 125 mètres carrés (bât. 1), associant des maçonneries à une ossature en bois et à un garnissage en terre. Placé exactement au centre de l'aire sacrée, il est constitué d'une cella, abritant les restes arasés d'un socle solidement fondé, et d'une galerie. Le plan centré de cet édifice est typique de ce qu'il est d'usage d'appeler un " temple de tradition indigène ou fanum "; termes usuels (Van Andringa, 2002, p. 106) auxquels il serait préférable de substituer celui d'aedes (Ibid, p. 103 et Scheid, 2005b, p. 59) pour désigner la construction de Saint-Martin, qui se compose d'une cella et d'une galerie périphérique.

\section{La cella}

Elle est de plan rectangulaire selon un axe de développement nord-sud, avec une longueur de 7 mètres pour une largeur de 6,50 mètres. Ces dimensions apparaissent courantes dans les départements voisins, et bien au-delà (Fauduet, 1993b), mais restent rares pour le Calvados au regard des quelques exemples récapitulés dans le tableau 1. 
Figure 8 : Saint-Martin-des-Entrées : plan de détail du temple (bâtiment 1). Figure 8: Saint-Martin-des-Entrées: detailed plan of the temple (building 1).

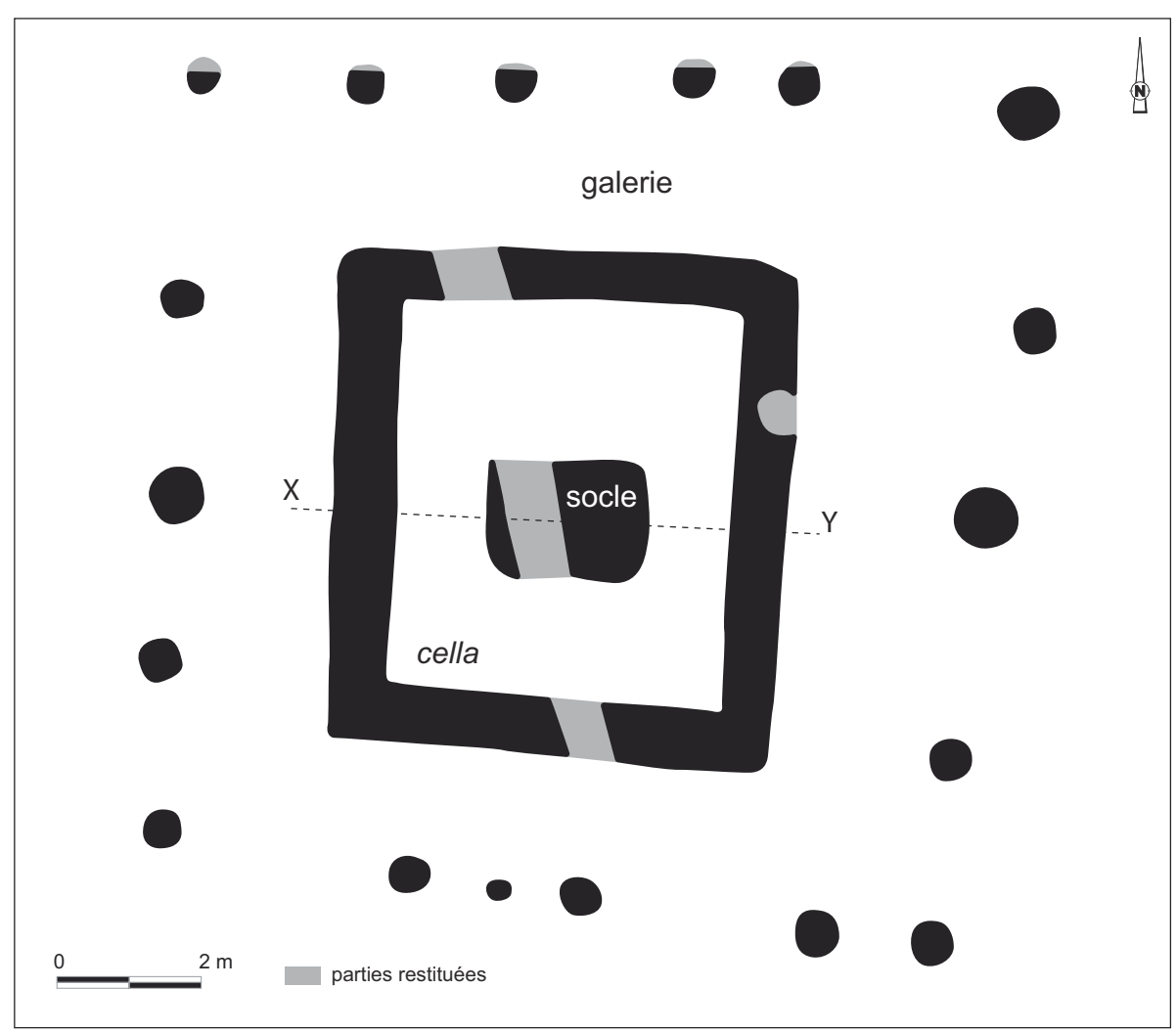

Tableau 1 : Les cellae aux dimensions comparables dans quelques sanctuaires du GrandOuest.

Table 1: The cellae with similar dimensions in sanctuaries in the West of France.

\begin{tabular}{|c|c|c|c|c|}
\hline Région & Département & Commune & $\begin{array}{l}\text { Dimensions de } \\
\text { la cella }\end{array}$ & Ref. Biblio. \\
\hline \multirow{3}{*}{ Bretagne } & Côtes-d'Armor & Plestin-les-Grèves & $7.30 \times 6.70 \mathrm{~m}$ & Fauduet 1993b \\
\hline & \multirow{2}{*}{ Morbihan } & Allaire & $6.50 \mathrm{~m}$ de côté & Fauduet 1993b \\
\hline & & Rieux & $7 \times 6.50 \mathrm{~m}$ & Fauduet 1993b \\
\hline \multirow{4}{*}{ Basse-Normandie } & \multirow{2}{*}{ Calvados } & Caen & $6.20 \times 5 \mathrm{~m}$ & Marin 1989 \\
\hline & & Touffréville & $7.70 \mathrm{~m}$ de côté & Coulthard 2000 \\
\hline & Manche & Montaigu-la-Brisette & $8.50 \mathrm{~m}$ de côté & $\begin{array}{l}\text { Paez-Rezende } \\
2003\end{array}$ \\
\hline & Orne & Nécy & $6 \mathrm{~m}$ de côté & $\begin{array}{l}\text { Besnard-Vauterin } \\
2006\end{array}$ \\
\hline \multirow{10}{*}{ Haute-Normandie } & \multirow{5}{*}{ Eure } & Beaumont-le-Roger & $6.50 \mathrm{~m}$ de côté & Fauduet 1993b \\
\hline & & Caudebec-les-Elbeuf & $6.50 \mathrm{~m}$ de côté & Fauduet 1993b \\
\hline & & Heudreville & $7.70 \mathrm{~m}$ de côté & Fauduet 1993b \\
\hline & & Louviers & $7 \times 6 \mathrm{~m}$ de côté & Fauduet 1993b \\
\hline & & $\begin{array}{l}\text { Saint-Ouen-de- } \\
\text { Thouberville }\end{array}$ & $6 \mathrm{~m}$ de côté & Fauduet 1993b \\
\hline & \multirow{5}{*}{ Seine-Maritime } & Harfleur & $6.50 \times 6 \mathrm{~m}$ & Fauduet 1993b \\
\hline & & La Londe & $6.50 \times 6 \mathrm{~m}$ & Fauduet 1993b \\
\hline & & Oissel & $7 \times 6.50 \mathrm{~m}$ & Fauduet 1993b \\
\hline & & Orival & $7 \times 6 \mathrm{~m}$ & Fauduet 1993b \\
\hline & & Vatteville-la-Rue & $7 \times 6.50 \mathrm{~m}$ & Fauduet 1993b \\
\hline \multirow{2}{*}{ Pays-de-la-Loire } & Sarthe & Aubigné-Racan & $7.60 \mathrm{~m}$ de côté & Fauduet 1993b \\
\hline & Mayenne & Entrammes & $6.50 \times 6 \mathrm{~m}$ & Fauduet 1993b \\
\hline
\end{tabular}


Les fondations et les murs de la cella, ou tout au moins les soubassements, sont construits en petit appareil calcaire selon le mode de la "pierre sèche ». Ils sont faiblement fondés à 0,30 mètre en dessous de la première assise et utilisent, à cet effet, des moellons et des petits blocs sur deux ou trois rangées. Le module des moellons calcaires utilisés en fondation est bien plus important que celui des parements de l'élévation, qui ne semblent pas davantage utiliser des pierres de taille bien régulières et calibrées, mais plutôt des moellons grossièrement apprêtés. Fondations et élévations semblent avoir une largeur identique de 0,70 mètre (fig. 9). La présence de mortier n'est attestée que dans les tranchées de récupération des murs. Il devait être mis en œuvre pour les lits de pose des assises de l'élévation et le garnissage des joints des parements. La partie haute des élévations était peut-être en torchis ou pisé.

\section{La galerie du déambulatoire}

D'une emprise de 11,50 mètres par 11 mètres, la galerie respecte la forme et l'axe de développement de la cella qu'elle entoure intégralement. Elle est construite à partir d'une ossature de bois matérialisée par dix-sept trous de poteau, dont les diamètres varient entre 0,30 et 0,90 mètre, pour des profondeurs échelonnées entre 0,10 et 0,40 mètre, et possédant ou non des calages de pierres calcaires. L'intervalle entre les poteaux est inférieur ou égal à 3 mètres et aucun mur de liaison n'a été repéré. Les façades est et ouest sont dotées de cinq poteaux, tandis que les façades nord et sud en dispose de six. Au nord et au sud, en raison de la mise en place d'un poteau supplémentaire, les intervalles sont plus aléatoires et oscillent entre 1 et 2,50 mètres, provoquant au final une déformation de la géométrie générale de la galerie. L'espace de circulation autour de la cella présente une largeur moyenne de 2 mètres et aucune entrée n’a pu être localisée. L'existence d'un sixième poteau sur deux façades aurait pu être assimilée à ce type de dispositif, mais le décalage qu'il impose par rapport à l'axe de symétrie du temple et du socle n’appuie guère cette hypothèse.

\section{Le socle}

Située au centre de la cella, une fosse grossièrement rectangulaire de 2,20 mètres par 1,80 mètre, d'orientation est-ouest, profonde de 0,50 mètre par rapport au seuil de décapage (fig. 9) et remplie de débris de calcaire et de mortier, s'apparente aux restes d'une fondation de socle de piédestal. Cet aménagement est assez comparable à celui mis au jour au centre de la cella du fanum de la première période (construction vers le milieu du I $^{\text {er }}$ siècle) du sanctuaire des Vaux-de-la-Celle à Genainville (Val-d'Oise) et apparenté aux " restes d'un aménagement destiné à supporter le socle de la statue de culte?» (Mitard, 1994, p. 46).

\section{Les autres bâtiments et aménagements divers (fig. 10)}

À côté du temple, le sanctuaire est doté d'au moins trois autres bâtiments, l'un maçonné et les deux autres sur poteaux. Sur toute la surface de la cour, des creusements de type fosses, carrières et trous de poteau, viennent compléter la nomenclature des vestiges associés à la morphologie et à l'évolution du sanctuaire.

\section{Les autres édifices}

À une vingtaine de mètres à l'ouest du temple, il ne subsiste du bâtiment 2 que deux lambeaux de fondations maçonnées en pierres sèches; la première formant l'angle
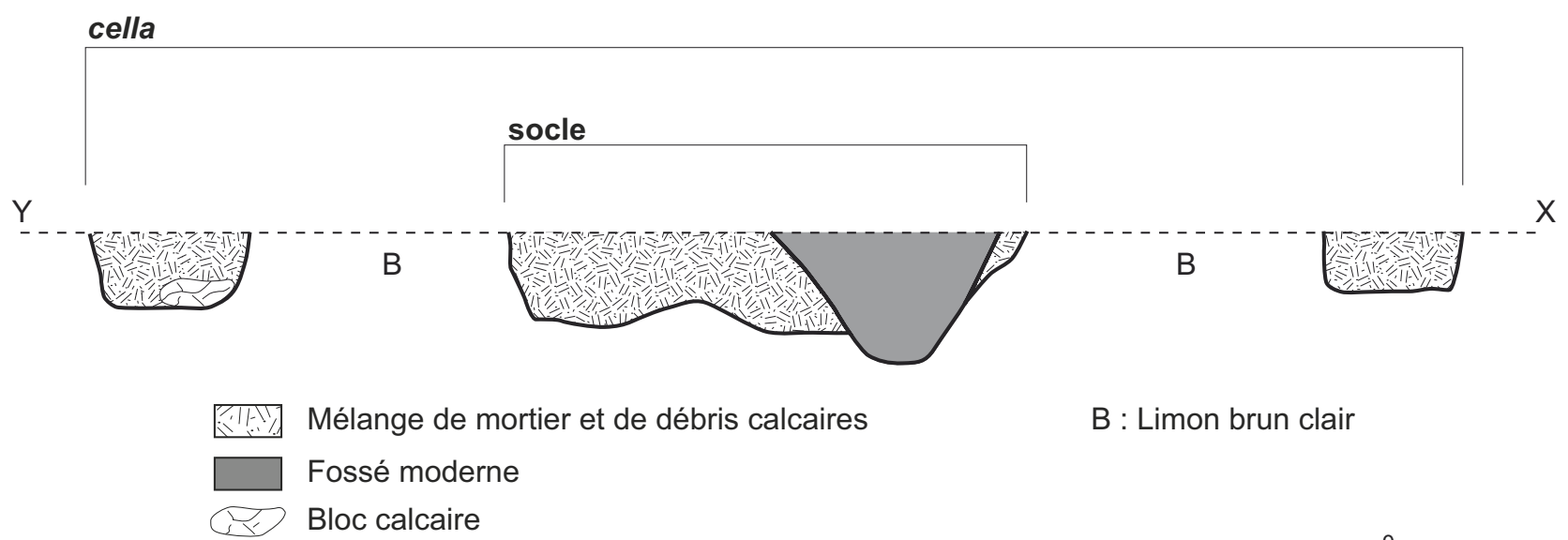

Mélange de mortier et de débris calcaires

B : Limon brun clair

Fossé moderne

Bloc calcaire

Figure 9 : Saint-Martin-des-Entrées : morphologie et stratigraphie des fondations de la cella et du socle.

Figure 9: Saint-Martin-des-Entrées: morphologie and stratigraphy of the cella foundations and its base. 


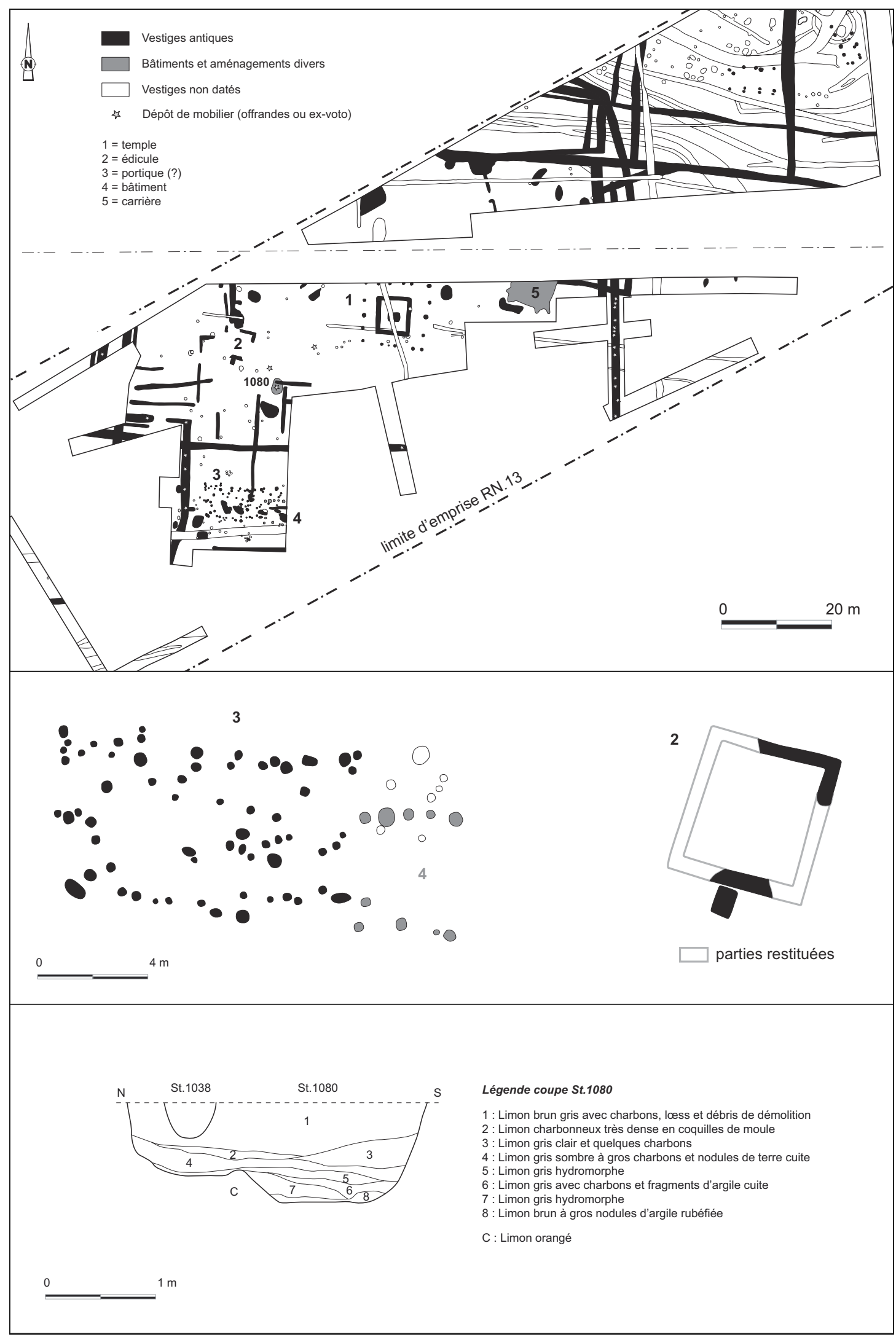

Figure 10 : Saint-Martin-des-Entrées : les bâtiments et les aménagements complémentaires du sanctuaire. Figure 10: Saint-Martin-des-Entrées: the buildings and the other structures of the sanctuary. 
nord-est et l'autre un tronçon de la façade sud. Ils permettent de restituer un plan rectangulaire de 5,40 mètres par 5 mètres (axe nord-est/sud-ouest), comparable à ceux des édicules ou chapelles du sanctuaire des Hernies à Macé (Leclerc, 2007, p. 108-109). Comme eux, il est ici accompagné d'un massif quadrangulaire de 1 mètre par 0,76 mètre, construit en plaquettes calcaires et placé devant la façade méridionale, au contact de la fondation. Ces aménagements ont été interprétés, à Macé, comme les seuils des chapelles sur lesquels avaient déposées les offrandes. L'état fragmentaire de cet édifice ne permet pas d'aller plus loin dans l'interprétation fonctionnelle.

Les deux autres édifices sont caractérisés par des ossatures de bois restituées parmi un amas de 77 trous de poteau, concentrés sur une centaine de mètres carrés le long de la limite sud de la cour. De forme rectangulaire, le bâtiment 3 se développe suivant un axe est-ouest et se présente comme le plus vaste du site avec ses 10 mètres par 5 . Il est implanté au débouché de l'entrée sud-ouest du second péribole. Il est composé d'au moins 21 trous de poteau dont les profondeurs préservées dans les formations superficielles sont en moyenne de 0,30 mètre. De même forme, le bâtiment 4 est accolé au pignon oriental du précédent. Il est constitué d'au moins 9 trous de poteau délimitant une emprise de 4,40 sur 3,60 mètres, orientée sur l'axe est-ouest.

Les exemples les mieux documentés faisant mention de tels groupements de poteaux proviennent rarement des fouilles d'habitats, mais plutôt de celles des sanctuaires où, d'ailleurs, la juxtaposition avec la limite du péribole n'est pas rare (Fauduet, 1993b, p. 105). Pour le Nord de la France, on citera entre autres celui d'Estrées-Saint-Denis dans l'Oise (Woimant, 1985) ; les autres exemples proviennent d'Allemagne : Sontheim/Brenz (Weber, 1994), et de Belgique : Wijnegem et Wiijshagen (Cuyt, 1987; Maes et Van Impes, 1986, cités par Cabuy 1994). Partout, ils sont considérés comme des édifices annexes. Malgré tout, pour les annexes, c'est la construction en dur qui prédomine, même si quelques mentions font état de "structures en matériaux périssables ». Celles de Saint-Martin ne dérogent pas à cette incapacité presque partout reconnue de leur conférer une quelconque destination, faute de mobilier ou d'indices plus tangibles. Les hypothèses récurrentes sont celles qui les destinent à une fonction d'accueil des pèlerins ou les apparentent à l'un de ces "portiques » qui constituent l'équipement monumental le plus courant.

\section{Les fosses}

Ces creusements sont le plus souvent ovales et peuvent atteindre 3,60 mètres de long. Manifestement, leur fonction première fut sans doute l'extraction de limon, pour ensuite servir de dépotoirs où se concentrent les dépôts de mobilier les plus importants et, plus particulièrement, les rejets de céramiques. Sur ce point, la fosse 1080 est la plus emblématique car relativement vaste et profonde $(2,90 \times 1,80 \times 1 \mathrm{~m}$; fig. 10). La stratigraphie y révèle une alternance de rejets à forte charge charbonneuse, livrant de grandes quantités de céramiques, et de dépôts hydromorphes sans grand mobilier.

\section{Une carrière ou une mare}

Positionné sur la frange orientale du sanctuaire, un vaste creusement $\left(\mathrm{n}^{0} 5\right)$ de 7,70 mètres par 7 mètres, très grossièrement quadrangulaire (axe nord-est/sud-ouest), aux bordures festonnées, semble relié à un fossé pouvant assurer une alimentation ponctuelle en eau. Le comblement argileux gris est sans conteste d'origine hydromorphe et oriente sa fonction, soit vers une réserve d'eau de type mare, soit vers une zone d'extraction de limon ou de préparation des torchis ou pisés en lien avec la restructuration du sanctuaire. La mise en place et le fonctionnement de cette structure interviendraient entre les deux phases du péribole, selon les observations stratigraphiques et les quelques céramiques collectées dans le comblement ou à sa surface.

\section{Les trous de poteau dissociés des architectures}

En dehors des éléments composant les édifices méridionaux, ou bien encore la galerie du temple, une trentaine de trous de poteau se répartissent dans l'aire sacrée. Malgré des morphologies similaires, ils ne permettent la restitution d'aucun plan cohérent. Plusieurs sont groupés de manière confuse, quelques-uns sont au contraire très isolés alors que d'autres sont manifestement révélateurs de creusements réalisés sur la longue durée. Même si certains côtoient d'autres vestiges comme l'édicule ou les fossés de partition, il s'avère difficile d'interpréter tous ces éléments en lien avec l'activité du sanctuaire.

\section{LES DÉPÔTS ET REJETS DE MOBILIER}

La céramique découverte sur le site de Saint-Martin-desEntrées constitue le mobilier prédominant. Elle se distingue par ses volumes assez significatifs et par un bon, voire un excellent état de conservation. Dans quelques contextes, dont ceux qui sont présentés, les rejets apparaissent de type " primaire " ou plus précisément, " semi-primaire ${ }^{1}$ ".

1. Ce type de rejet livre des poteries dispersées plus ou moins fragmentées mais pouvant être presque entièrement remontées, à la différence d'un rejet secondaire qui livre des céramiques très fragmentées et incomplètes, attestées par un ou quelques fragments seulement. Le rejet "semi-primaire " est notamment démontré ici par les nombreux recollages de poteries dont les fragments proviennent de différences niveaux de comblements. 
Cependant, dans de nombreuses fosses ou portions de fossés, les dépotoirs sont "secondaires", présentant les signes d'un probable séjour à l'air et d'une dispersion plus ou moins importante des fragments. Ces états de conservation variables découlent avant tout des différents modes de rejets ainsi que de l'éventuel arasement des structures fossoyées.

Le mobilier non céramique, et particulièrement l'instrumentum métallique, est assez peu fréquent, bien que régulièrement présent dans les échantillonnages. Il est souvent assez corrodé et par conséquent fragile. Le verre est quasiment absent des lots de mobilier. La faune, enfin, est présente dans quasiment tous les creusements, mais dans un très mauvais état de conservation qui ne permettait ni de la prélever, ni de la préserver.

\section{Les dépôts de céramique dans les fossés des périboles et l'aire sacrée}

Des poteries ont été disposées une à une en position verticale dans le fossé 1086 (fig. 5, péribole 1), ou bien sous l'aspect de vases écrasés en association avec des ossements de faune dans le fossé 1023 (Ibid.). Dans ces cas, on remarque l'absence flagrante de formes basses ouvertes. Il est difficile d'affirmer d'un point de vue céramologique qu'il y ait des productions ou des aménagements spécifiques aux pratiques cultuelles, mais il semble évident que de tels dépôts en masse s'apparentent davantage à des offrandes qu'à de simples rejets domestiques. On observe ainsi que les poteries ont été déposées et non jetées, ou bien alors écrasées sur place (bris rituel?), voire regroupées par type comme l'ensemble de sigillées du fossé 1071. Quant à l'association vases/ restes de faune, souvent mentionnée dans les sanctuaires, elle évoque fort logiquement le rite des repas cultuels. Par ailleurs, deux fonds de vases en céramique commune grise étaient posés dans la cour et plus précisément intégrés dans l'horizon à pédogenèse, l'un à mi-distance entre le temple et l'édicule, et l'autre à 4 mètres au sud-est de l'édicule. Ces deux " offrandes " potentielles sont attribuées à la phase 1 du sanctuaire. À noter enfin, la présence d'un vase miniature en association avec une coupelle sigillée portant la lettre $P$ gravée sur la panse, tous deux déposés dans le fossé 1054. La signification de cet assemblage et de l'inscription (une initiale?) demeurent énigmatiques et ne sont pas nécessairement le reflet d'une intention à caractère religieux.

\section{L'instrumentum}

Il est constitué d'un stylet en bronze, de type instrument d'oculiste (aiguille à cataracte), d'un bracelet en bronze, de fragments de verrerie, des clous d'une semelle de chaussure et d'une pince à épiler dans le fossé 1054 (phase 2). Cette faible quantité, qu'il faut toutefois relativiser du fait de l'exploration partiel du site, ne permet pas à ces quelques éléments d'être significatifs sur le plan des expressions rituelles qui ont pu présider à leur dépôt.

\section{Les rejets de faune dans le fossé oriental du péribole 1 (fig. 11)}

Une concentration d'ossements de faune, probablement issue de la consommation de bovidés et accumulées sur environ 2 mètres de long, a été observée dans le remplissage médian du fossé 1023 . Très dégradé, cet ensemble ne présente pas de connexion anatomique et évoque davantage un relief de repas évacué dans le fossé du péribole lors de sa première phase de fonctionnement que d'une offrande sous la forme d'un quartier d'animal. Il s'agit principalement qu'une douzaine de côtes et de quelques autres éléments non identifiés. Un tel volume relève davantage du banquet que du simple repas. Le lieu, l'homogénéité du lot, la sélection des morceaux, la quantité et l'association avec de grands fragments de vases en céramique commune concourent ainsi à attribuer un caractère rituel à ce dépôt.

\section{Chronologie du sanctuaire ET ÉVOLUTION DU RÉPERTOIRE CÉRAMIQUE}

\section{Les antécédents}

Un enclos d'habitat et du parcellaire de La Tène moyenne/ finale sont implantés sur la marge nord-est de l'enceinte cultuelle. Mais on note un hiatus de près d'un siècle dans les

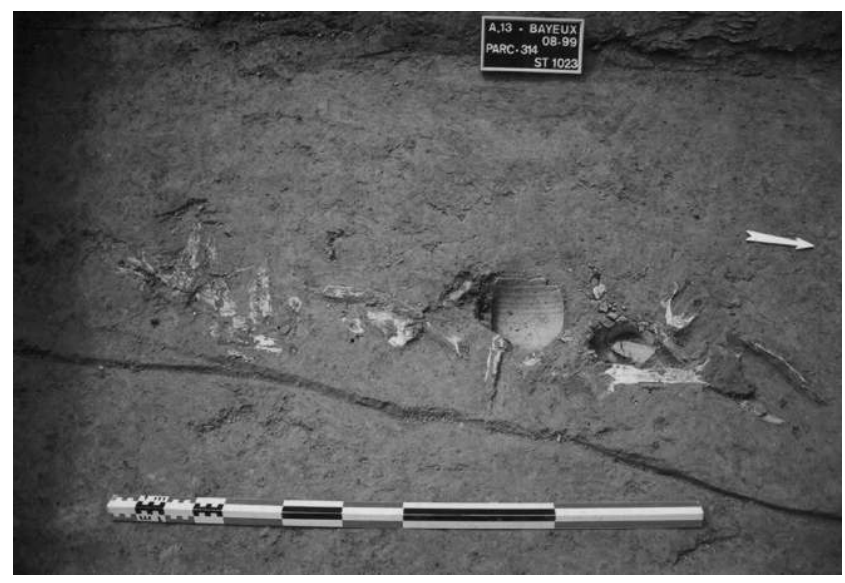

Figure 11 : Saint-Martin-des-Entrées : le dépôt de faune et de céramiques dans le fossé oriental du péribole 1.

Figure 11: Saint-Martin-des-Entrées: the deposit of animal bone and pottery in the eastern ditch of peribol 1. 
séries céramiques entre les deux ensembles de vestiges. Il est donc difficile d'envisager le sanctuaire comme une solution de continuité entre l'occupation laténienne et l'occupation gallo-romaine.

\section{La période de construction et la première phase de fonctionnement : milieu du $\mathrm{I}^{\mathrm{er}}$ siècle-début du II ${ }^{\mathrm{e}}$ siècle (fig. 12)}

La première phase de fonctionnement qui s'étend entre le milieu du $\mathrm{I}^{\mathrm{er}}$ siècle et le début du $\mathrm{II}^{\mathrm{e}}$ siècle intègre, au sein du péribole 1, le temple à galerie, peut-être l'édicule (bât. 2), quelques fossés de subdivision et au moins la fosse 1080 qui livre l'ensemble céramique le mieux documenté pour la période. Le sanctuaire, est à l'évidence déjà entré dans son plein fonctionnement lorsque se constitue le dépôt de la fosse 1080. Avec l'appui de quelques artefacts résiduels, la construction peut être raisonnablement située vers le milieu ou le deuxième tiers du $\mathrm{I}^{\mathrm{er}}$ siècle. Le comblement stratifié de cette grosse fosse a livré un important mobilier céramique dans l'ensemble bien conservé (462 tessons représentant au moins 65 individus), dont le détail des quantifications et proportions est récapitulé dans le tableau 2. De multiples

\begin{tabular}{|l|l|l|l|l|}
\hline Catégories / Types & N.R. & $\%$ & N.M.I. & $\%$ \\
\hline Sigillée & 8 & 1,73 & 5 & 7,7 \\
\hline assiette Drag. 18 (L G.) & 2 & & 1 & \\
\hline coupelle Drag. 27 (L G.) & 1 & & 1 & \\
\hline bol moulé Drag. 29 b (L G.) & 1 & & 1 & \\
\hline bol moulé Drag. 30 (L G.) & 1 & & 1 & \\
\hline bol moulé Drag. 37 (L G.) & 1 & & 1 & \\
\hline indét. (L G.) & 2 & & & \\
\hline Paroi fine engobée & 2 & 0,4 & 1 & 1,5 \\
\hline gobelet à décor « en épingles » (Centre Gaule) & 2 & & 1 & \\
\hline Terra Nigra & 21 & 4,5 & 4 & 6 \\
\hline assiettes à lèvre pendante Ménez 11/16 & 9 & & 2 & \\
\hline Bol caréné à fond en pointe Ménez 110a & 7 & & 1 & \\
\hline bol ovoïde à décor guilloché & 5 & & 1 & \\
\hline Céramique commune lustrée & 38 & 8,2 & 7 & 10,7 \\
\hline bols à décors guillochés & 15 & & 2 & \\
\hline assiette imitant le type Ménez 11/16 & 6 & & 1 & \\
\hline assiette imitant le type Ménez 22 & 5 & & 1 & \\
\hline assiette à « rebord » & 5 & & 1 & \\
\hline assiette imitant le type Ménez 29/30 & 1 & & 1 & \\
\hline pot ou gobelet imitant le type Ménez 146 & 6 & & 1 & \\
\hline Céramique engobée & 39 & 8,4 & 6 & 9,2 \\
\hline cruches à engobes blancs & 11 & & 2 & \\
\hline pot à anses à engobe blanc & 5 & & 1 & \\
\hline pot indét. à engobe blanc & 1 & & 1 & \\
\hline assiette à lèvre décorée et à engobe blanc & 1 & & 1 & \\
\hline grosse cruche ou amphore (?) à engobe blanc & 1 & & 1 & \\
\hline vrac de tessons indét. à engobe blanc & 20 & & & \\
\hline Céramique commune & 353 & 76,4 & 41 & 63 \\
\hline pots de formes diverses & 52 & & 14 & \\
\hline écuelles à profils en « S » & 30 & & 4 & \\
\hline grandes bouteilles & 15 & & 3 & \\
\hline Faisselles & 10 & & 3 & \\
\hline forme ouverte indét. bol ( ?) & 3 & & 1 & \\
\hline petites assiettes ou « coupes » & 4 & & 2 & \\
\hline vrac de tessons indét. en céram comm. sombre & 218 & & 5 & \\
\hline petits pots en pâtes claires & 16 & & 6 & \\
\hline mortiers en pâtes claires & 4 & & 2 & \\
\hline forme décorée indét. en pâte claire & 1 & & 1 & \\
\hline Amphore & 1 & 0,2 & 1 & 1,5 \\
\hline Dressel 20 & 1 & & 1 & \\
\hline Total & 462 & 99.83 & 65 & 99.6 \\
\hline & & & & \\
\hline
\end{tabular}

${ }^{1}(\mathrm{~L} \mathrm{G})=$. La Graufesenque

Tableau 2: Comptage des céramiques de la fosse 1080. Table 2: Inventory of pottery from pit 1080. recollages réalisés entre le mobilier provenant des différentes couches démontrent la réalité d'un seul et même tas de déchets, qui a sans doute été dispersé dans plusieurs séquences de comblement. Outre la qualité de conservation de la plupart des poteries et l'association conséquente qu'elles constituent, l'un des principaux intérêts de cet ensemble est d'ordre chronologique : il s'avère en effet être le contexte gallo-romain le plus ancien qui ait été découvert dans l'emprise de la fouille, avec le fossé 1092 (non présenté), mais ce dernier n’a pas livré d'association aussi conséquente.

\section{La céramique sigillée (fig. 13)}

Elle a pour particularité un mauvais état de conservation qui contraste avec celui de beaucoup de poteries communes dont certaines ont pu être presque entièrement reconstituées. Malgré ce fait, elle ne montre aucune distorsion chronologique avec le reste de la céramique associée, céramique à paroi fine engobée, Terra Nigra ou autres. Il s'agit donc probablement de rejets de nature différente ayant provoqué une conservation très inégale.

Les formes en présence révèlent une petite association pertinente : une sigillée moulée de type Drag. 29 b (non illustré) associée à un rare Drag. 30 (cf. forme no 1080-1), accompagnées de sigillées lisses de types Drag. 27 et 18 (cf. $\mathrm{n}^{\circ} 1080-3$ ). Issues des ateliers de La Graufesenque, ces formes, qui représentent les constantes du répertoire sigillé de la deuxième moitié du i ${ }^{\text {er }}$ siècle, sont ici associées à une forme "tardive ", un bol moulé Drag. 37 (cf. nº 1080-2) issu des mêmes ateliers, qui fixe par là même un terminus post quem pour la formation du dépotoir et son enfouissement : en effet, le Drag. 37 n'a pas été fabriqué avant les années 70-80. On remarque cependant l'absence des formes appartenant aux services flaviens, particulièrement abondantes entre la fin du $\mathrm{I}^{\mathrm{er}}$ et le début du $\mathrm{II}^{\mathrm{e}}$ siècle. Ainsi constitué, cet ensemble de sigillées fournit un repère chronologique fiable pour la deuxième moitié du $\mathrm{I}^{\mathrm{er}}$ siècle.

\section{La céramique à paroi fine engobée (fig. 13)}

Elle est présente avec les restes d'un unique gobelet ovoïde à décor " en épingles " réalisé à la barbotine (cf. n 1080-4). Ce dernier montre la technique de fabrication caractéristique des ateliers du centre de la Gaule : pâte jaunâtre légèrement micacée rehaussée d'un engobe brunâtre. Ce type de produit est bien connu entre les dernières décennies du $\mathrm{I}^{\mathrm{er}}$ siècle et le tout début du $\mathrm{II}^{\mathrm{e}}$ siècle (Brulet et al., 2010).

\section{La Terra Nigra (fig. 14)}

Tout comme la sigillée, elle renvoie à un répertoire assez classique de l'époque et de cette partie du territoire : assiettes à lèvre pendante correspondant au type Ménez 11/16 (2 ex. cf. n $\left.{ }^{\circ} 1080-5\right)$, associées à un bol caréné à fond en pointe cor- 


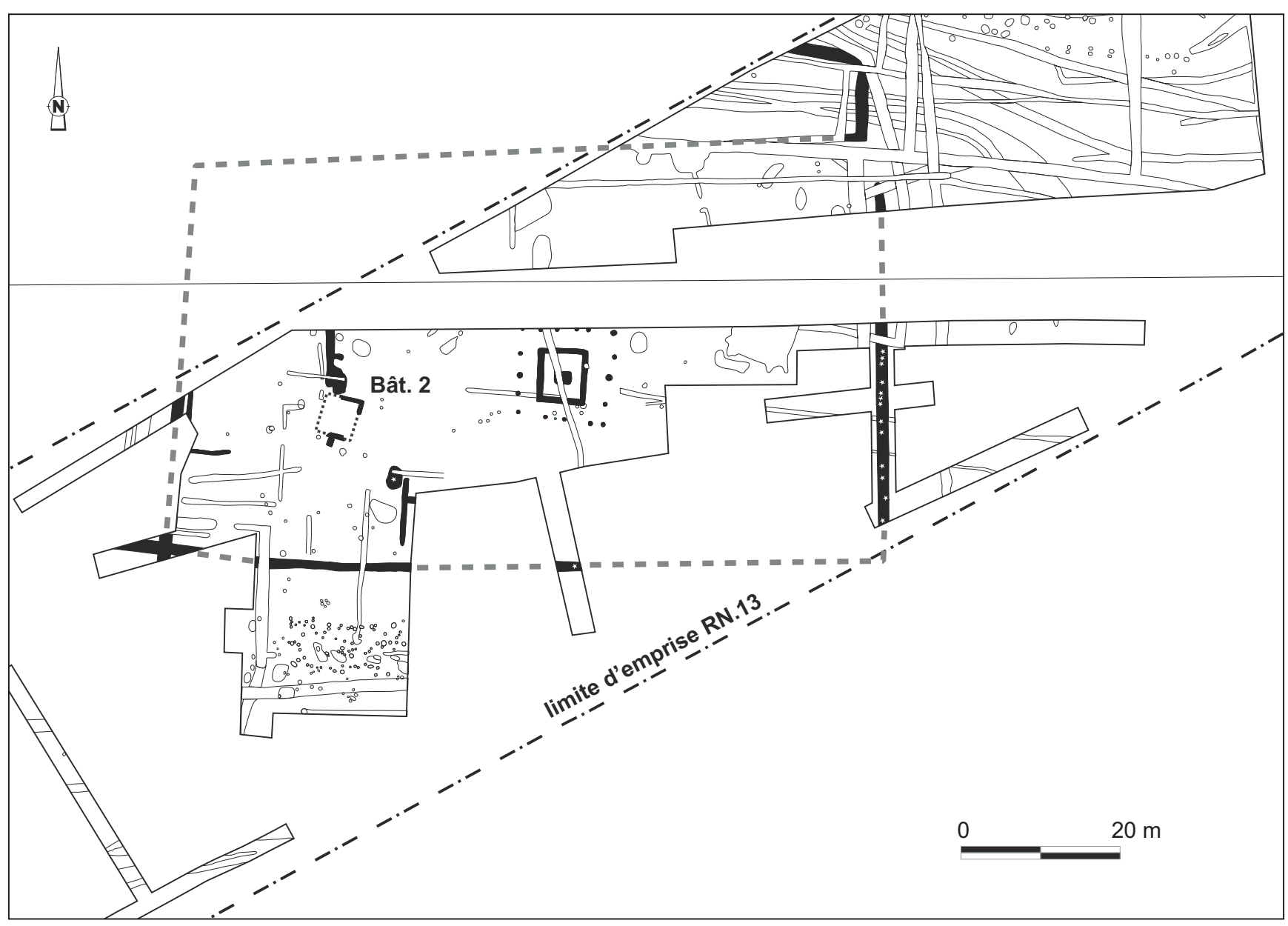

Figure 12 : Saint-Martin-des-Entrées : la période de construction et la première phase de fonctionnement du sanctuaire (milieu du $\mathrm{I}^{\mathrm{er}}$ siècle - début du $\mathrm{II}^{\mathrm{e}}$ siècle).

Figure 12: Saint-Martin-des-Entrées: the construction and the first phase of the sanctuary's use (middle of the $1^{\text {st }}$ century-beginning of the $2^{\text {nd }}$ century $A D)$.

respondant au type Ménez 110, variante a (1 ex. cf. n ${ }^{\circ} 1080$ $6)$. Ces deux types de formes paraissent représenter une association constante durant le dernier tiers du $\mathrm{I}^{\mathrm{er}}$ siècle dans l'ouest de la Gaule. Elles sont associées à une forme apparemment moins répandue, une sorte de bol ovoïde décoré de guillochis, trop mal conservé pour être figurée, qui ne semble pas correspondre à un type actuellement défini dans le répertoire de la TN mais qui montre la même pâte rougeâtre à surface brun-noir que les deux types précédents, suggérant une même origine. Celle-ci ne peut être évaluée précisément, mais semble, malgré une certaine ressemblance, différente des productions champenoises.

\section{La céramique commune lustrée (fig. 14)}

Elle se distingue de la céramique fine d'importation, et particulièrement de la Terra Nigra, par une technique de fabrication plus simple, que ce soit au niveau de l'élaboration de la pâte que du façonnage du vase ou sa finition (lus- trage). Ce type de production concerne ici des céramiques variées, dont la plupart possèdent comme particularité de reprendre certaines formes du répertoire de la Terra Nigra, souvent parfaitement copiées au point de rendre la confusion possible lors d'une identification visuelle rapide ou bien lors d'une simple représentation graphique. Ainsi les poteries découvertes dans cette fosse révèlent la prépondérance de formes imitant directement la Terra Nigra : assiette à bord oblique imitant la forme précoce type Ménez 22 (est-elle résiduelle?2 Elle est pourtant bien conservée; cf. no 1080 12), assiette à lèvre pendante imitant le type Ménez 11/16 (cf. ${ }^{\circ} 1080-11$ ), et pot ou gobelet reprenant globalement la forme du type Ménez 146 (nº 1080-13). De manière générale, ces formes montrent des pâtes plutôt fines de couleur blanchâtre à surfaces grises ou gris-clair. Leur polissage/

2. Elle est encore attestée vers le milieu du I ${ }^{\text {er }}$ siècle à Ifs (Simon $e t$ al., 2002 ; « horizon $5 »)$ 


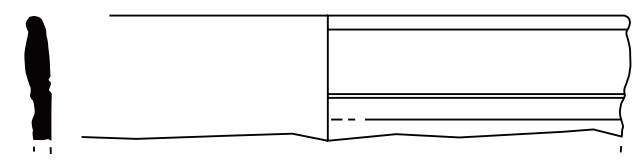

1080-1 (si)
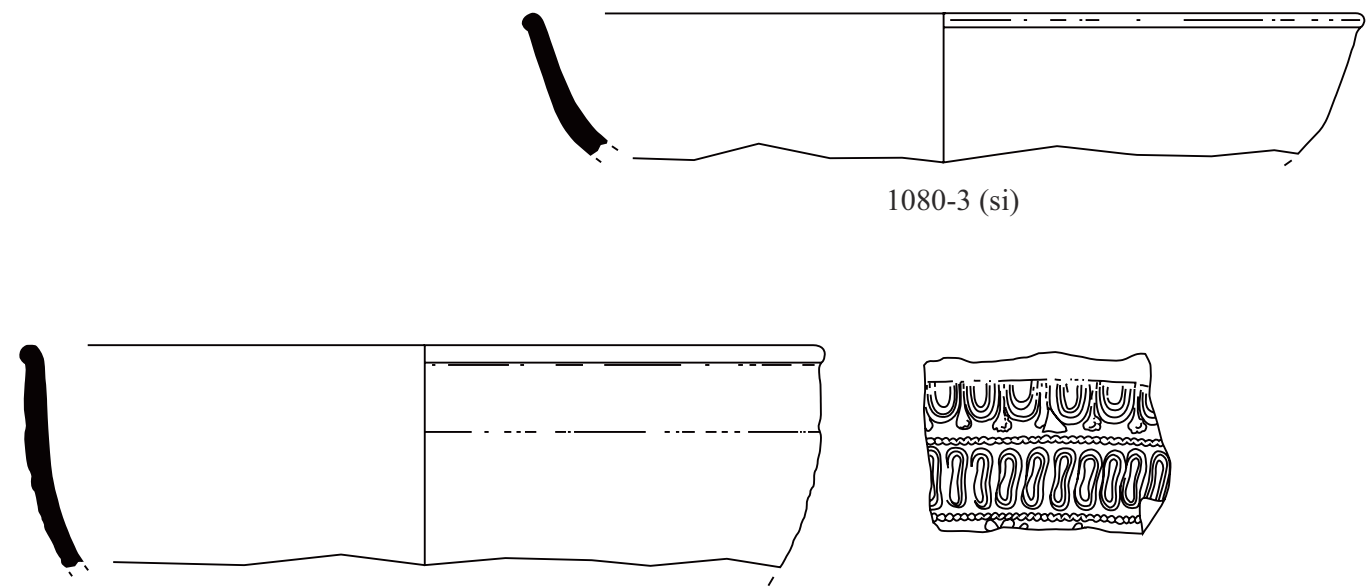

1080-2 (si)
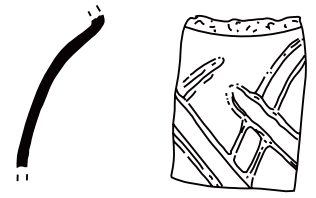

$1080-4(\mathrm{pfe})$

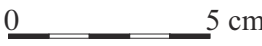

Figure 13 : Saint-Martin-des-Entrées : sigillée du Sud de la Gaule et paroi fine engobée du Centre de la Gaule (deuxième moitié du $\mathrm{I}^{\text {er }}$ siècle).

Figure 13: Saint-Martin-des-Entrées: samian ware from south of Gaul and slipwares from the centre of Gaul (2nd half of the $1^{\text {st }}$ century AD).

lustrage est plus ou moins soigné. L'absence de différence très nette entre leurs pâtes respectives rend possible une même origine, sans toutefois permettre une identification assurée ni une suggestion sur leur provenance. Deux types distincts de formes regroupées dans cette catégorie de céramique " commune lustrée " semblent cependant n'avoir que de lointains rapports avec la Terra Nigra : les plus explicites sont deux exemplaires de bol presque caréné, montrant chacun une même décoration guillochée, mais apposée à deux endroits différents du corps de la poterie (cf. $n^{\circ} 1080-9$ et 10). Ils trouvent un parfait parallèle avec des exemplaires découverts à Bretteville-l'Orgueilleuse où l'auteur signalait lui aussi cette parenté avec la Terra Nigra (fosse 3003; Navarre, 1997). De réalisation assez sommaire, les deux poteries découvertes ici appartiennent visiblement à la même production (pâte beige/brunâtre à surface plus ou moins sombre), qui apparait différente de celles reconnues sur les autres formes de la céramique lustrée. Le dernier type en présence est une assiette à rebord (cf. $\left.\mathrm{n}^{\circ} 1080-8\right)$ qui n'est pas sans rappeler la forme définie par Y. Ménez sous le numéro 44, sans toutefois lui correspondre réellement. Cette différence typologique avec la TN semble confirmée par la technologie de cette assiette qui reste rudimentaire, bien qu'elle mette en œuvre un traitement de surface (pâte fine blanchâtre, à surface gris clair).

\section{La céramique engobée (fig. 15)}

Cette catégorie rassemble des poteries très différentes, tant au niveau de leur forme que de leur usage. Mais elles ont en commun la même application externe d'un engobe blanc plus ou moins épais, visant à donner un aspect extérieur clair, en palliant les couleurs orangées ou rougeâtres de leurs argiles après cuisson. Entre deux et trois productions différentes semblent pouvoir être ici identifiées. Cette technique concerne deux formes différentes de cruches (1 ex. figuré, $\mathrm{n}^{\circ} 1080-14$ ), et deux pots apparemment semblables (cf. $\left.\mathrm{n}^{\circ} 1080-15\right)$. Ces formes sont complétées par une unique assiette dont la lèvre est rehaussée d'un guillochis 


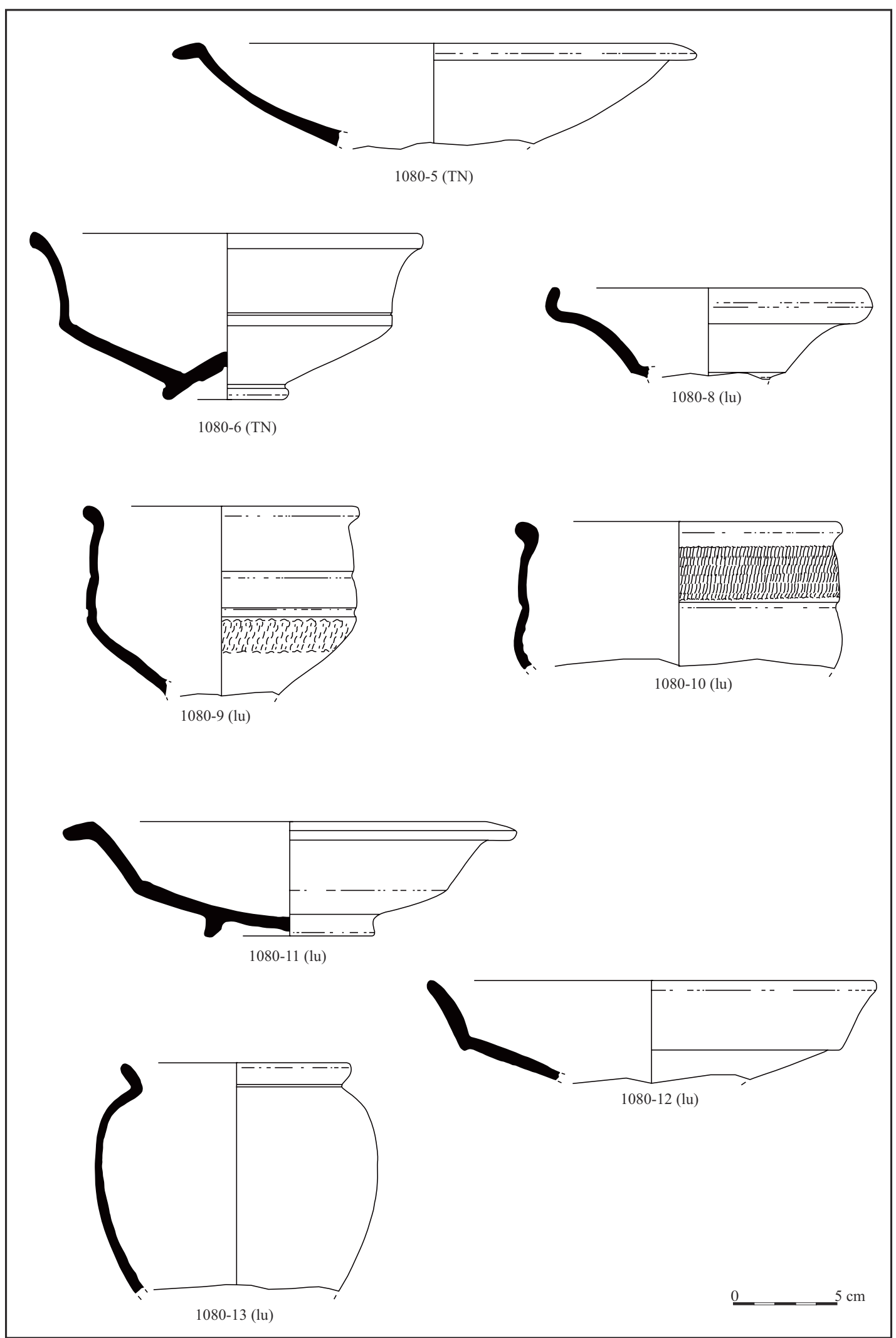

Figure 14 : Saint-Martin-des-Entrées : Terra Nigra et céramique commune sombre lustrée de la fosse 1080 (deuxième moitié du i ${ }^{\text {er }}$ siècle).

Figure 14: Saint-Martin-des-Entrées: Terra Nigra and dark polished pottery from pit 1080 (2 $2^{\text {nd }}$ half $1^{\text {st }}$ century). 


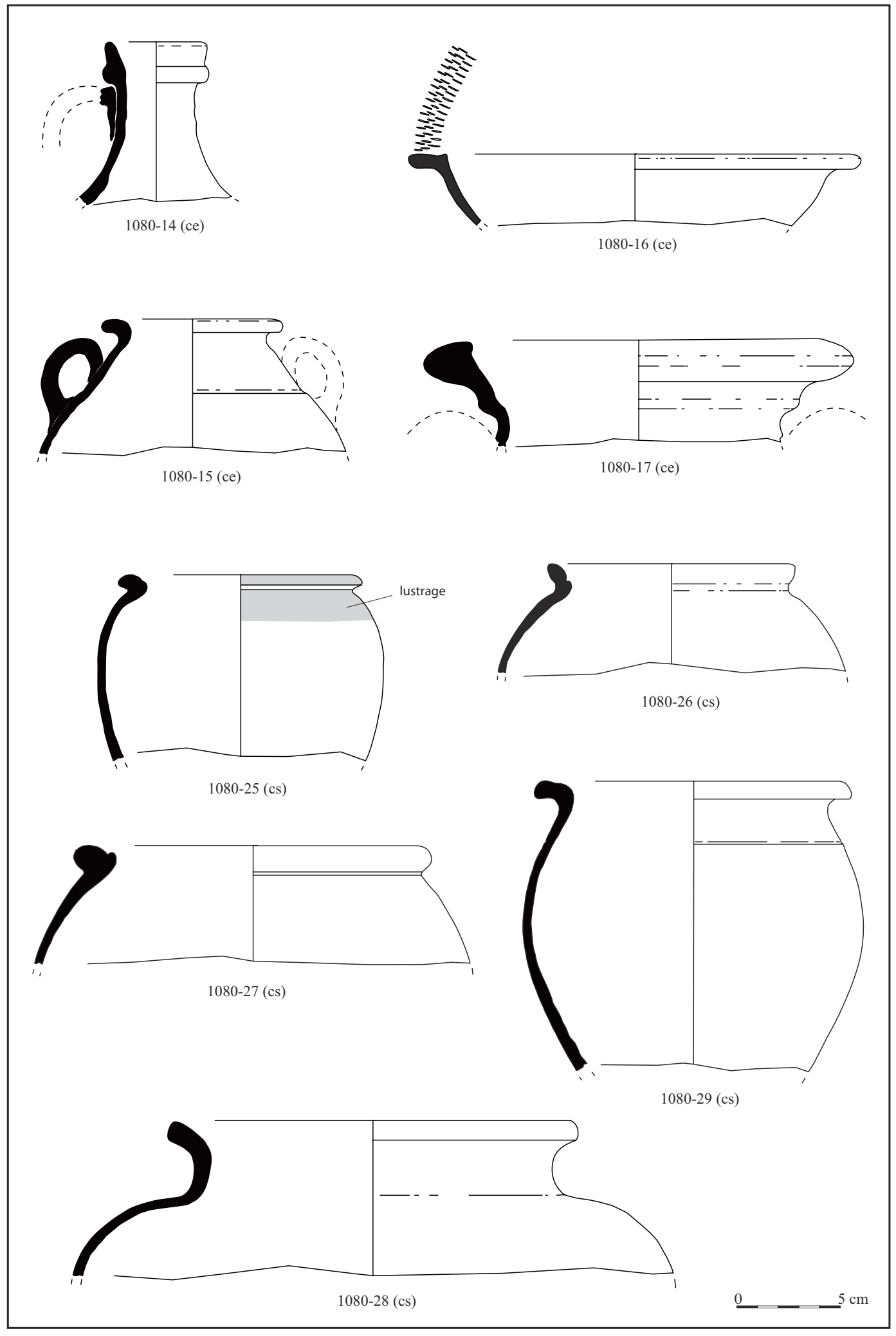

Figure 15 : Saint-Martin-des-Entrées : céramique claire engobée ( $\mathrm{n}^{\text {os }} 14$ à 17$)$, et principales variantes de pots en céramique commune sombre de la fosse 1080 (deuxième moitié du i ${ }^{\mathrm{er}}$ siècle).

Figure 15: Saint-Martin-des-Entrées: light slipware (N.14 to 17) and main types of dark polished pots from pit 1080 ( $2^{\text {nd }}$ half $1^{\text {st }}$ century). 
(cf. $\mathrm{n}^{\circ} 1080-16$ ), ainsi qu'une probable amphore dont l'origine est inconnue ( $\left.\mathrm{n}^{\circ} 1080-17\right)$. La forme la plus curieuse de cet ensemble de poteries engobées est sans aucun doute le pot à anses $n^{\circ} 15$. Il correspond en effet à une forme référencée à Haltern comme le type 62, ainsi que par E. Gose comme le type 421-424. Elle est bien attestée dans le camp augustéen d'Haltern ou dans celui d'époque tibérienne d'Oberadern. Mais il semble que le modèle ait perduré durant une bonne partie du ${ }^{\text {er }}$ siècle, et notamment jusqu'à l'époque flavienne à Trèves (Gose, 1950). Sans disposer de nouveaux éléments à ce sujet, il nous est impossible de dire si la forme découverte dans cette fosse 1080 (d'autant qu'il semble y en avoir deux) correspond à un résidu de l'époque augustéenne ou bien si elle est en place. Notons que son bon état de conservation (état de surface et fragmentation) semble plutôt contradictoire avec l'idée d'une forme nettement plus ancienne.

\section{La céramique commune (fig. 15 à 17)}

Elle révèle un répertoire particulièrement varié de formes dont aucun type ne paraît réellement dominer, même si quelques modèles sont plus représentés que d'autres. Cette diversité contraste avec le phénomène observé au sein des ensembles du $\mathrm{II}^{\mathrm{e}}$ siècle qui montrent une céramique commune nettement moins variée, dominée par un ou deux types très particuliers, présents avec de nombreux exemplaires (cf. le fossé 1054). Si la gamme des pots à cuire est sans aucun doute la plus abondante, avec 20 exemplaires de ce type de vase (14 sont en pâtes grises et 6 en pâtes claires), elle montre l'association de poteries assez différentes, tant dans leurs formes que dans leur procédé de fabrication (et notamment la cuisson). Toutes appartiennent néanmoins à ce que l'on pourrait appeler la "tendance typologique " de cette période en Gaule du Nord (n ${ }^{\circ} 1080-25$ à 32). En effet, ces formes trouvent bon nombre de parallèles dans les répertoires voisins. Plusieurs de ces pots, assez semblables bien que déclinés sous des tailles différentes (cf. $\mathrm{n}^{\circ} 1080$ 29, 30 et 31), sont visiblement issus de la même production, aussi représentée par plusieurs autres types de formes, qu'elles soient bouteilles, écuelles à profils en " $S$ ", faisselles et peut-être aussi quelques-unes des assiettes en céramique lustrée. Quelques petits pots globulaires possèdent comme particularité d'avoir reçu un traitement de surface sur l'encolure, visant à donner un aspect brillant à cette partie de la poterie. Cette technique concerne un pot en pâte grise $\left(\mathrm{n}^{\circ} 1080-25\right)$ et au moins deux pots en pâtes claires (1 ex. figuré, $\left.\mathrm{n}^{\circ} 1080-33\right)$. Elle fait vraisemblablement référence aux céramiques badigeonnées au mica, assez largement répandues à cette époque, mais apparemment absentes de ce site. Ces pots montrent chacun des pâtes atypiques par rapport aux pâtes courantes rencontrées dans cet ensemble, traduisant sans doute des approvisionnements ponctuels. Le reste des poteries communes associées dans l'ensemble 1080 révèle plusieurs types de formes très différentes et qui paraissent pour la plupart relativement classiques de l'époque, bien que quelques-unes ne trouvent actuellement aucune comparaison. Si certaines sont attestées avec trois ou quatre exemplaires, d'autres sont uniques. Les formes les plus classiques de cette période sont les écuelles à profil en " $S$ ", dont quatre exemplaires sont présents dans ce contexte (3 ex. illustrés, cf. $\mathrm{n}^{\circ} 1080-18,19$ et 20) : elles constituent en effet les composantes systématiques des répertoires galloromains de Gaule du Nord. Il en est de même pour deux mortiers en pâte claire dont la forme du bord est très classique de l'époque. L'un deux (n ${ }^{\circ} 1080-34$ ) possède une pâte jaune et tendre caractéristique d'une production picarde, sans doute de Noyon, dont la diffusion est aujourd'hui bien avérée dans toute l'inter région. Beaucoup moins répandues, trois exemplaires de bouteilles sont présentes ( 2 ex. illustrés, cf. $\mathrm{n}^{\circ} 1080-21$ et 22 ). De tailles variées, ces poteries montrent une silhouette et une technique de décoration en registre sur toute la partie supérieure qui reprend celles des bouteilles de la Terra Nigra gallo-belge. Mais elles semblent dépourvues de tout traitement de surface. Ces bouteilles sont visiblement issues de la même production qu'un certain nombre de formes découvertes dans cet ensemble, dont des formes de la céramique commune lustrée (et notamment le pot/gobelet $\mathrm{n}^{\circ} 13$ ), mais aussi de la céramique commune (écuelle en « $S » n^{\circ} 1080-19$, faisselle $n^{\circ} 1080-24$, pots $\mathrm{n}^{\circ}$ 1080-29 à 31).

Quelques autres poteries beaucoup plus rares complètent l'ensemble :

- Les plus significatives sont trois faisselles en céramique commune sombre, dont le fond bombé permettait la pose sur un autre récipient ( 1 ex. illustré, cf. $n^{\circ} 1080-24$ ). La présence de faisselles au $\mathrm{I}^{\mathrm{er}}$ siècle trouve quelques comparaisons, que ce soit en plaine de Caen, à Fleury-sur Orne (Simon et al., 2002), et dans l'Orne, à Sées, où ce type appartient semble-t-il à la Terra Nigra (Fichet de Clairfontaine et Gros, 1995) ou bien en Haute-Normandie où il peut aussi bien être le fait de poteries à pâtes claires qu'à pâtes sombres (Adrian, 1996). Ces faisselles semblent issues de deux productions distinctes, dont une est bien représentée au sein de ce contexte 1080 avec un éventail varié de poteries (écuelles, pots à cuire, bouteilles, gobelet lustré, et peut-être aussi assiette lustrée).

- Deux formes basses, peut-être des coupes, ferment l'éventail des poteries communes à pâtes sombres. L'une d'elles (n' 1080-23) apparaît rare. Elle semble appartenir à une production représentée aussi par plusieurs pots à cuire (dont les $n^{\circ} 1080-26$ et 28). 


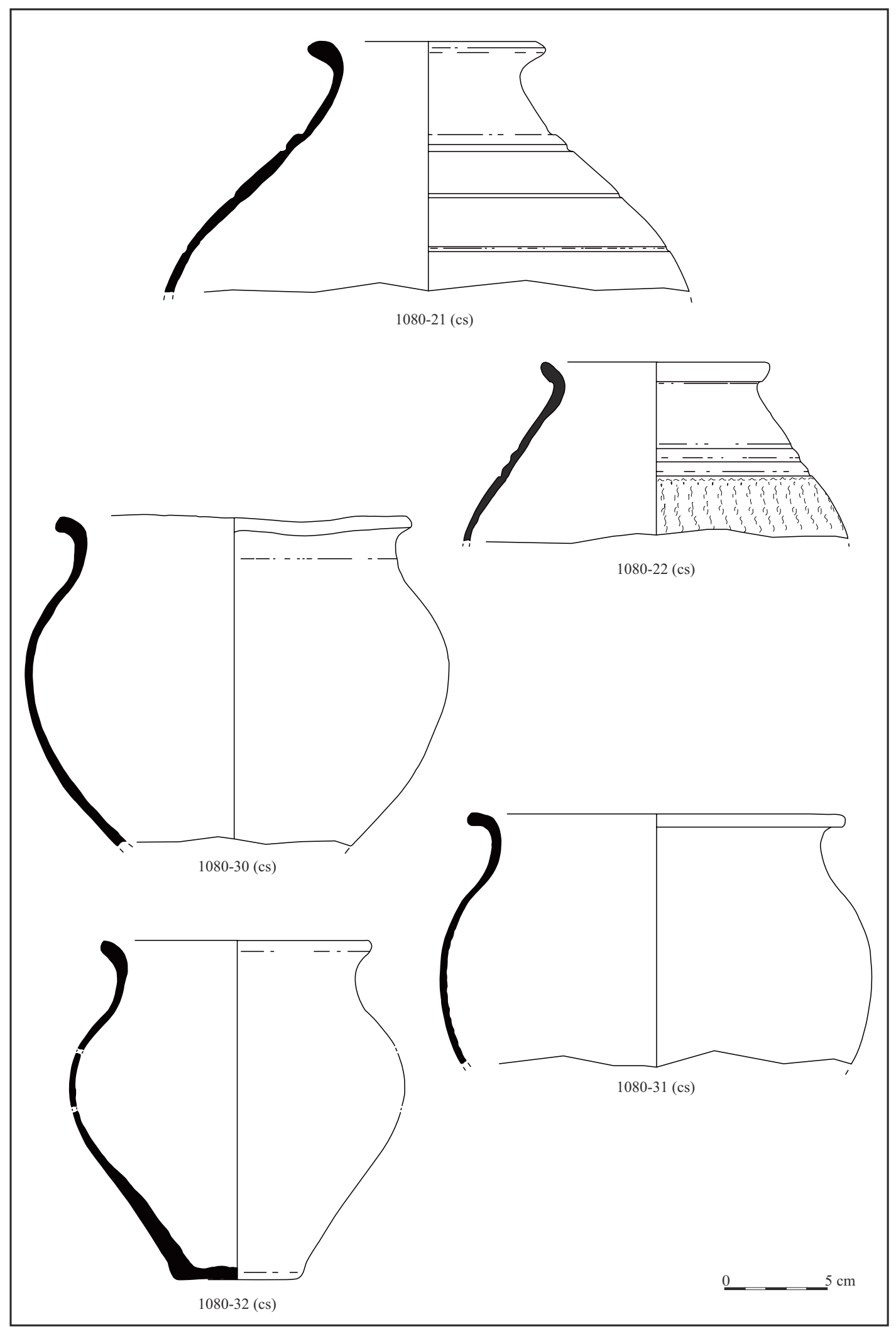

Figure 16 : Saint-Martin-des-Entrées : autres variantes de pots et bouteilles en céramique commune sombre de la fosse 1080 (deuxième moitié du i ${ }^{\text {er }}$ siècle).

Figure 16: Saint-Martin-des-Entrées: other types of pots and bottles (darkware) from pit 1080 (2nd half $1^{\text {st }}$ century). 


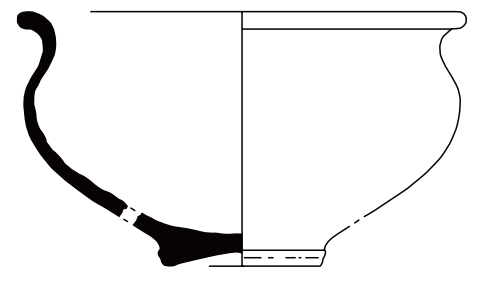

$1080-18(\mathrm{cs})$
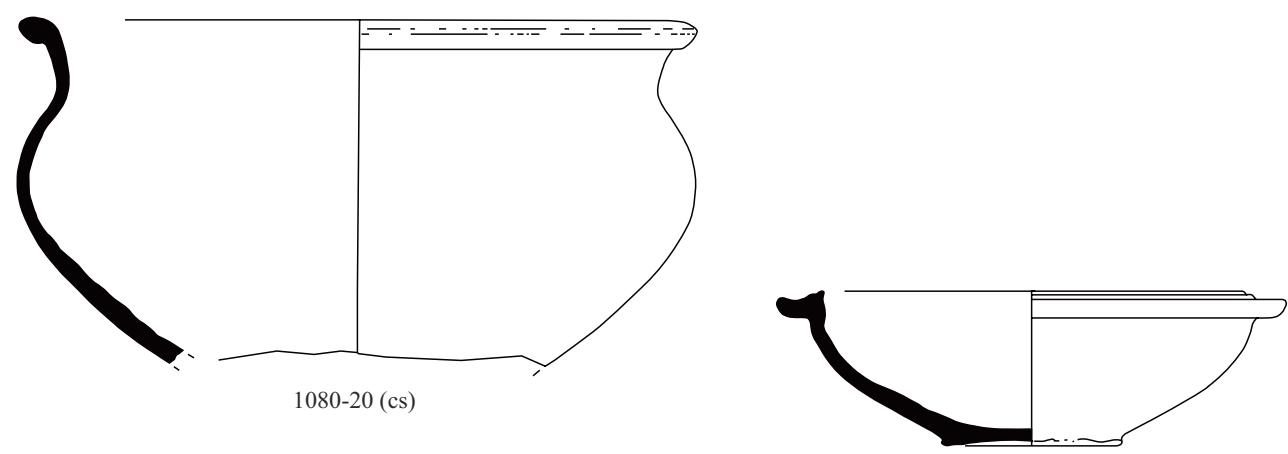

1080-23(cs)
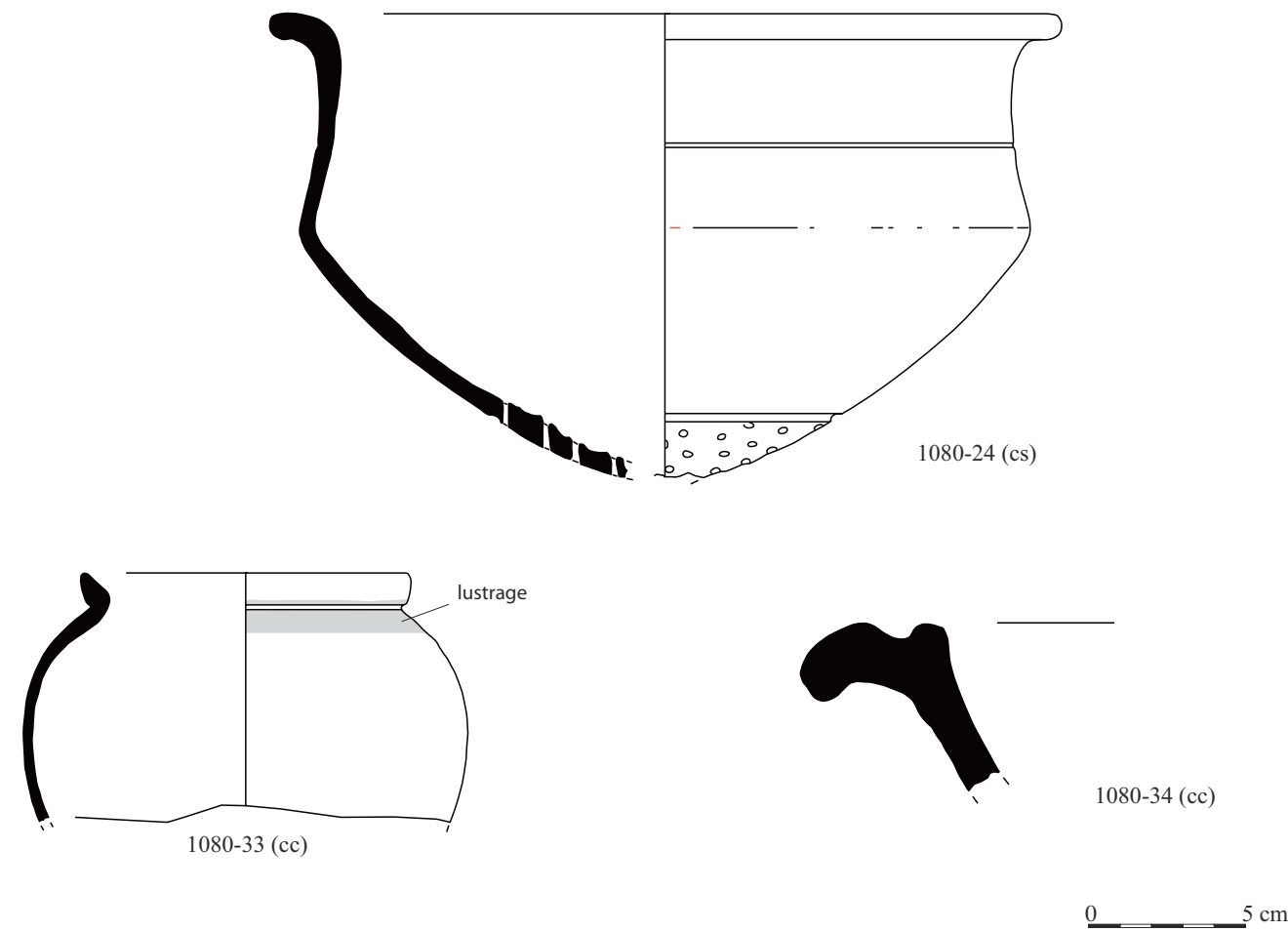

Figure 17 : Saint-Martin-des-Entrées : principales formes basses en céramique commune sombre et céramique à pâte claire ( $\mathrm{n}^{\mathrm{os}} 33$ et 34 ) de la fosse 1080 (deuxième moitié du $\mathrm{I}^{\mathrm{er}}$ siècle).

Figure 17: Saint-Martin-des-Entrées: main open forms in darkware and lighter fabrics (N.33 and 34) from pit 1080 ( $2^{\text {nd }}$ half $1^{\text {st }}$ century). 


\section{Chronologie de l'ensemble 1080}

Lassociation des formes ou productions dans cette fosse ne pose pas de problème particulier du point de vue chronologique. Seule l'éventuelle ancienneté de quelques modèles, comme l'assiette lustrée ${ }^{3} \mathrm{n}^{0} 1080-12$ ou le pot à anses et engobe blanc $\mathrm{n}^{\circ} 1080-15$, reste à préciser. Mais le mobilier d'importation, qu'il soit sigillé ou Terra Nigra, évoque clairement la deuxième moitié du $\mathrm{I}^{\mathrm{er}}$ siècle, tout en fixant nécessairement, de par la présence d'un bol moulé Drag. 37 de La Graufesenque, la datation ultime après les années 80 , un terminus que confirme la paroi fine engobée à décor « en épingles " du centre de la Gaule. L'absence de formes ou de productions sigillées plus tardives, particulièrement des services flaviens, ainsi que les caractères des formes, essentiellement celles de la Terra Nigra ou de la céramique commune lustrée, permettent toutefois d'exclure toute datation plus avancée vers le II ${ }^{\mathrm{e}}$ siècle.

\section{Les remaniements du début du $\mathrm{II}^{\mathrm{e}}$ siècle (fig. 18)}

La seconde phase de fonctionnement, qui couvre tout le II ${ }^{\mathrm{e}}$ siècle, se manifeste d'abord par l'agrandissement et la restructuration de l'aire sacrée, sous l'effet de la refondation du péribole et d'une complexification des subdivisions internes, et ensuite par l'enrichissement des équipements avec la création assurée des bâtiments 3 et 4, mais aussi le fonctionnement de l'édicule. De nombreux dépôts céramiques discriminants pour la chronologie sont effectués dans les fossés périmétriques, dont le fossé 1054 propose l'assemblage le plus emblématique. En effet, le comblement stratifié de ce fossé a livré un abondant mobilier céramique plus ou moins dispersé sur les 25 mètres de son tracé (1 696 tessons, représentant au moins 200 individus). L'étude a mis en évidence plusieurs recollages entre des fragments de poteries provenant des différents niveaux du comblement, ainsi que

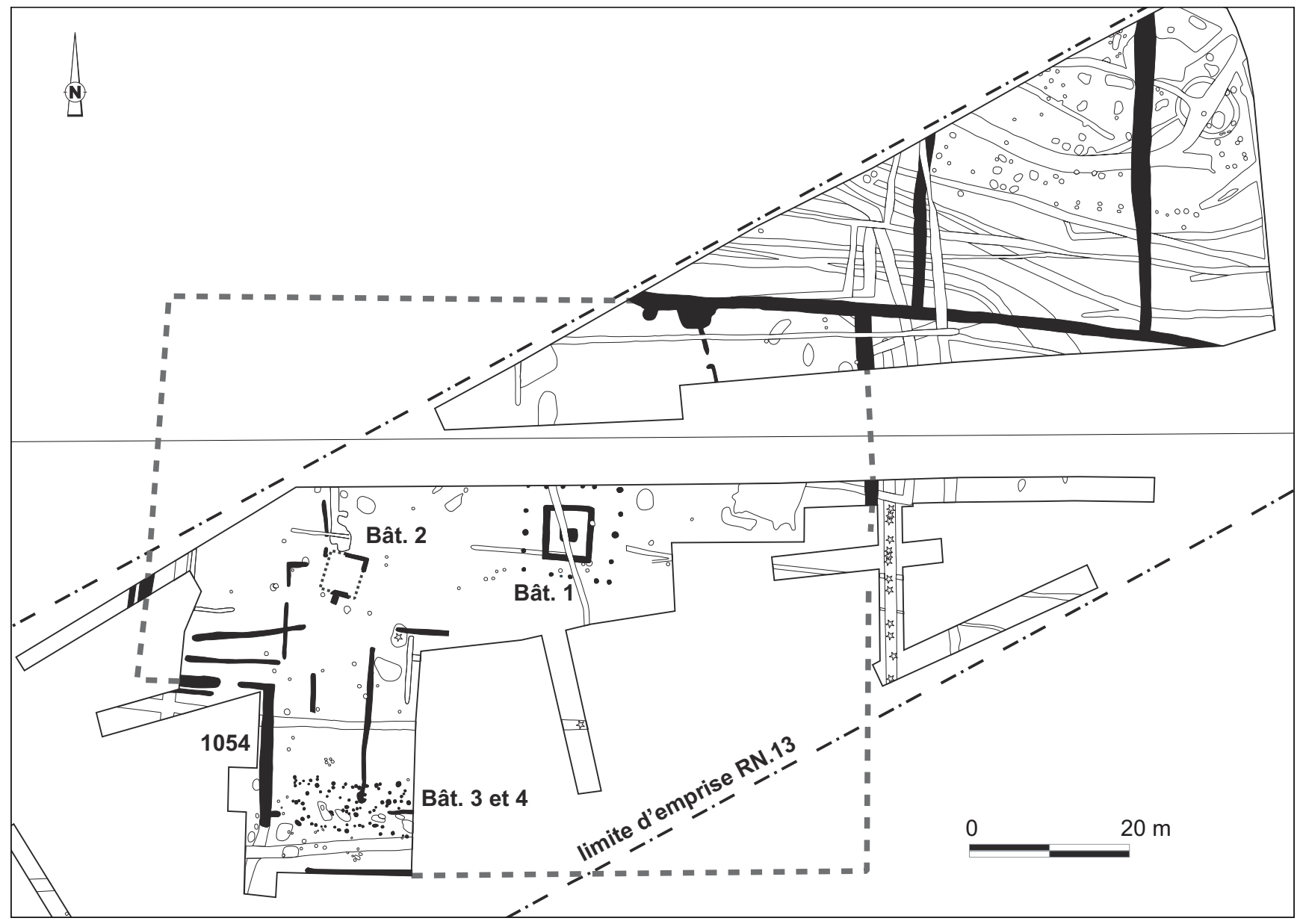

3. Cette résidualité semble cependant peu vraisemblable, d'autant que ce type d'assiette à bord haut et incurvé est connu dans le Nord de la France, et notamment à Baralle, près d'Arras, durant la deuxième moitié $\mathrm{du} \mathrm{I}^{\text {er }}$ siècle (Hosdez et Jacques, 1989).
Figure 18 : Saint-Martin-des-Entrées : les remaniements du sanctuaire au début du II $^{\mathrm{e}}$ siècle.

Figure 18: Saint-Martin-des-Entrées: reorganisation of the sanctuary at the beginning of the $2^{\text {nd }}$ century. 
de plusieurs portions du fossé ${ }^{4}$, même espacées. Ces collages démontrent la réalité de déchets de même origine, plus ou moins dispersés et étalés par les phénomènes naturels de l'érosion ou bien lors de l'entretien du fossé. Ils nous ont en même temps amené à réaliser un NMI très « strict » : le risque de compter plusieurs fois une même poterie dispersée en plusieurs endroits du comblement est en effet apparu important. Le détail des comptages et des proportions est présenté dans le tableau 3.

\section{La céramique sigillée (fig. 19)}

Elle constitue un ensemble conséquent avec au moins 29 formes répertoriées, représentant environ $14 \%$ du NMI total. La contribution de Richard Delage (Inrap) permet de préciser la plupart des origines de ces sigillées, presque exclusivement issues des ateliers du centre de la Gaule, tout en mettant en évidence une chronologie particulièrement précise pour la formation de l'ensemble. Les deux types de formes les plus abondants sont le bol moulé Drag. 37 (6 exemplaires) et l'assiette à bord évasé de type Drag. 31/Lezoux no 54-56 (6 exemplaires). Si toutes sont attribuables au groupe des ateliers du centre de la Gaule, l'origine de quelques-unes de ces formes ne peut être précisée. Ceci concerne notamment le Drag. $37 \mathrm{n}^{\circ} 2$, d'origine indéterminée. Au moins deux Drag. 37 (dont le vase $\mathrm{n}^{\circ}$ 1054-1) peuvent être attribués aux productions de Cinnamus du courant du II ${ }^{\mathrm{e}}$ siècle (vers 130160), tandis qu'un autre vase du même type (non illustré) évoque celles de Paternus II, durant la deuxième moitié du II $^{\mathrm{e}}$ siècle. Quelles que soient leurs origines, les six vases moulés en présence évoquent une période comprise entre le $2^{\mathrm{e}}$ et le $3^{\mathrm{e}}$ quart du II siècle. Il n’y a ainsi aucune production du début ou, au contraire, de la fin du II siècle. La même homogénéité apparait dans les formes lisses associées, et notamment les six exemplaires de la forme d'assiette Drag. 31/Lezoux 54-56 (4 ex. figurés, cf. n ${ }^{\circ} 1054-4$ à 7). Leurs pâtes évoquent en effet les productions du milieu du $\mathrm{II}^{\mathrm{e}}$ siècle ou du troisième quart. Là encore, l'absence des productions de la fin du $\mathrm{II}^{\mathrm{e}}$ siècle. est notoire. Par des différences de tailles, plusieurs formes lisses semblent constituées de petits " services " : ainsi deux exemplaires de coupelles à rebord Lezoux 44 (dont le ${ }^{\circ}$ 1054-8) peuvent être associés à une assiette Lezoux 45 (n $\left.n^{\circ} 1054-9\right)$. Cette dernière forme est issue d'un atelier du centre resté indéterminé. Léventualité d'un "service " concerne aussi deux coupelles Lezoux 24 (dont une coupelle estampillée "Samilli. $M$ », cf. $\mathrm{n}^{\circ}$ 1054-10), attribuables aux ateliers des Martres-de-Veyre, et une épaisse coupe Lezoux 25 à anses ( ${ }^{\circ}$ 1054-11), vraisemblablement issue de Lezoux. Le reste des sigillées découvertes dans ce fossé 1054 se compose d'un

4. Ce fosse 1054 a été fouillé par sections d'environ 2 mètres de long, et le mobilier a été enregistré de la même manière.

\begin{tabular}{|l|l|l|l|l|}
\hline Catégories / Types & N.R. & $\%$ & N.M.I. & $\%$ \\
\hline Sigillée & 55 & 3,2 & 29 & 14,5 \\
\hline bols Drag. 37 (Lez. + Centre) & 9 & & 6 & \\
\hline assiettes Drag. 31 / Lezoux 54-56 (Centre) & 13 & & 6 & \\
\hline coupes Lezoux 44 (Centre) & 9 & & 2 & \\
\hline jattes Drag. 38 (Lez. + Centre indét.) & 2 & & 2 & \\
\hline coupelle Lezoux 24 estamp. (Martres de V.) & 1 & & 1 & \\
\hline coupe Lezoux 24 ou 25 (Lez.) & 1 & & 1 & \\
\hline tèle Drag. 43 / Curle 21 (Est ?) & 1 & & 1 & \\
\hline assiette Curle 15 / Lezoux 45 (Centre indét.) & 5 & & 1 & \\
\hline coupelle Lezoux 50 (Centre) & 4 & & 1 & \\
\hline coupe Drag. 33 (Centre) & 1 & & 1 & \\
\hline coupe ou assiette Walters 79/80 (Centre) & 1 & & 1 & \\
\hline coupelle Lezoux 42 (Centre indét.) & 1 & & 1 & \\
\hline formes indét. (Centre + Lez.) & 6 & & 4 & \\
\hline coupe Drag. 36 (L G.) & 1 & & 1 & \\
\hline Paroi fine engobée & 7 & 0,4 & 4 & 2 \\
\hline gobelet « sablé » metallescent (Arg.) & 6 & & 3 & \\
\hline gobelet indét. (Centre) & 1 & & 1 & \\
\hline Céramique commune lustrée & 86 & 5 & 18 & 9 \\
\hline assiettes imitant le type sigillé Curle 23 & 31 & & 10 & \\
\hline petits gobelets imitant les parois fines & 22 & & 4 & \\
\hline pots ou « grands gobelets » ovoïdes & 31 & & 3 & \\
\hline Bol & 2 & & 1 & \\
\hline Céramique commune & 1535 & 90,5 & 147 & 73,5 \\
\hline gros pots ou « marmites » & 125 & & 30 & \\
\hline pots divers & 25 & & 15 & \\
\hline pot indét. décoré & 15 & & 1 & \\
\hline mortiers (à cuisson réductrice) & 31 & & 10 & \\
\hline écuelles à profil en « S » & 43 & & 6 & \\
\hline écuelles tripodes « hémisphériques » & 23 & & 6 & \\
\hline assiette à bord très évasé & 3 & & 1 & \\
\hline assiette à bord rentrant & 1 & & 1 & \\
\hline assiettes indét. & 7 & & 3 & \\
\hline couvercles & 10 & & 5 & \\
\hline jattes & 6 & & 3 & \\
\hline jatte à collerette & 5 & & 1 & \\
\hline écuelle carénée à décor ondé & 9 & & 1 & \\
\hline cruche indét. en pâte grise (à bec trèflé ?) & 2 & & 1 & \\
\hline formes indét. en céram. commune sombre & 104 & & 42 & \\
\hline vrac de tessons en céram commune sombre & 823 & & & \\
\hline cruches en pâtes claires & 293 & & 20 & \\
\hline petit pot en pâte claire & 10 & & 1 & \\
\hline Amphores & 13 & 0,8 & 2 & 1 \\
\hline Dressel 20 & 13 & & 2 & \\
\hline Total & 1696 & 99,9 & 200 & 100 \\
\hline
\end{tabular}

Tableau 3 : Comptage des céramiques du fossé 1054.

Table 3: Inventory of pottery from pit 1054.

éventail relativement varié de formes, le plus souvent attestées par un seul exemplaire :

- jattes à collerette Drag. 38 (2 ex. non illustrés). L'une de ces formes peut être attribuée aux productions de Lezoux datées de la première moitié du II siècle. Il s'agit de l'une des poteries les plus anciennes de l'ensemble.

- coupe Walters 79 ( ${ }^{\circ}$ 1054-12), vraisemblablement issue d'un atelier de l'Allier comme Terre-Franche ou bien Toulon-sur-Allier.

- coupelle Drag. 33 ( $\left.\mathrm{n}^{\circ} 1054-13\right)$.

- coupelle Lezoux 50 ( $\left.\mathrm{n}^{\circ} 1054-14\right)$, attribuable aux productions du début de la phase 7 de Lezoux. Cette forme est vraisemblablement l'une des sigillées, sinon la sigillée la plus récente de cet ensemble.

- coupelle Lezoux 42 ( $\mathrm{n}^{\circ}$ 1054-15).

- tèle Drag. 43 ou Curle 21 (non illustrée). Cette forme est la seule sigillée qui ne provienne pas du centre de la Gaule. Sa pâte évoque les productions de l'Est (?).

- coupe Drag. 36 à décor de "feuilles d'eau " (non illustrée). Issue des ateliers de La Graufesenque, cette forme est à l'évidence la poterie la plus ancienne, apparaissant même résiduelle par rapport à la datation ultime de l'ensemble. 


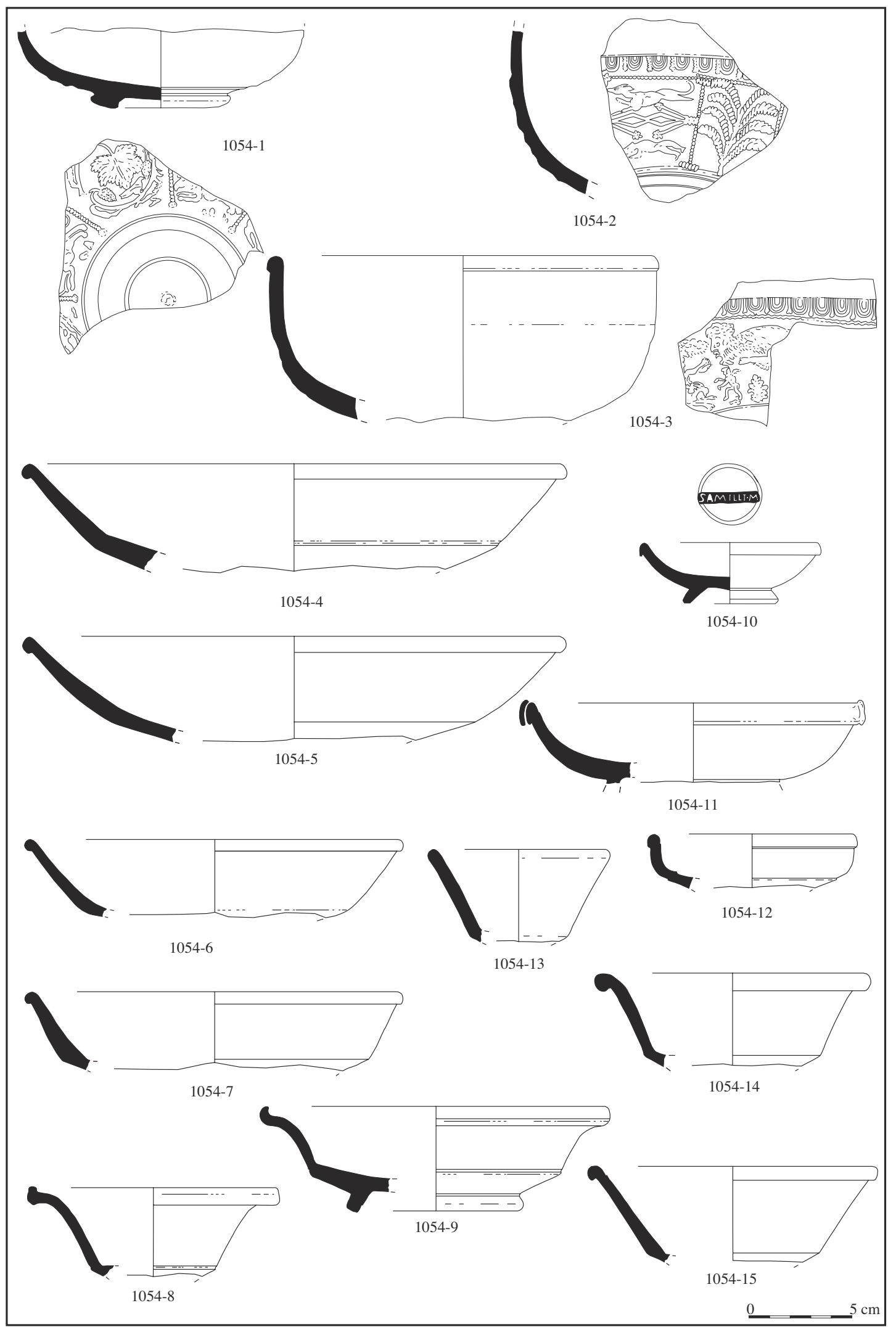

Figure 19 : Saint-Martin-des-Entrées : sigillée du Centre de la Gaule du fossé 1054 (courant du II ${ }^{\mathrm{e}}$ siècle). Figure 19: Saint-Martin-des-Entrées: Samian from the centre of Gaul from pit 1054 (2 $2^{\text {nd }}$ century). 
L'homogénéité chronologique de cet ensemble apparaît remarquable, et ceci malgré des états de conservation variables, imputables aux modes de rejets. Les deux sigillées les plus anciennes datent du début du II $^{\mathrm{e}}$ siècle (la coupe Drag. 36 de La Graufesenque) ou de la première moitié du $\mathrm{II}^{\mathrm{e}}$ siècle (une des jattes Drag. 38). Toutes les autres formes ( $\mathrm{n}=26)$, lisses ou moulées, évoluent dans une période comprise entre le milieu et le troisième quart $\mathrm{du} \mathrm{II}^{\mathrm{e}}$ siècle, soit un ensemble constitué et utilisé pendant une quarantaine d'années, mais recelant un très léger fond ancien (résiduel?) datant de la première moitié du $\mathrm{II}^{\mathrm{e}}$ siècle. L'absence de toute production sigillée plus tardive, par ailleurs présente sur le site (cf. le fossé 2041), est décisive : le terminus post quem peut ainsi être précisément fixé durant le troisième quart du II ${ }^{\mathrm{e}}$ siècle, soit vers les années 160/170-175, au plus tard. Sans apporter réellement d'élément supplémentaire, la céramique commune associée ne contredit pas cette appréciation : elle révèle elle aussi un léger "fond ancien " datable de la première moitié du $\mathrm{II}^{\mathrm{e}}$ siècle, tout en s'avérant homogène et contemporaine de la sigillée.

\section{La céramique à paroi fine engobée}

Elle est pratiquement inexistante avec seulement trois formes répertoriées (trop mal conservées pour être illustrées), et dont une apparaitt " ancienne " si ce n'est résiduelle. Elle révèle l'association de deux gobelets à décor projeté et engobe noir pourvu d'une couverte plus ou moins métallescente, attribuables aux ateliers argonnais, avec un gobelet indéterminé dont la pâte jaune recouverte d'un engobe noir évoque une production du centre de la Gaule. La forme caractéristique du fragment de fond conservé suggère qu'il s'agisse d'une série du début de l'époque antonine ${ }^{5}$. Ce gobelet tend à confirmer la présence, révélée au travers des sigillées, de quelques formes de la première moitié du II siècle, au sein de cet ensemble du fossé 1054 .

\section{La céramique commune lustrée (fig. 20)}

Elle forme une catégorie beaucoup plus conséquente que la céramique à paroi fine engobée avec au moins 18 formes répertoriées. Elle montre principalement des poteries directement inspirées des céramiques fines d'importation, sigillées ou parois fines et même Terra Nigra, associées à quelques formes plus spécifiques actuellement inédites. Les formes les plus nombreuses sont des assiettes dont la silhouette s'inspire plus ou moins fidèlement de l'assiette sigillée type Curle 23 (10 exemplaires) : certains exemplaires sont en effet des copies fidèles de la forme sigillée ( $\mathrm{cf}$. $\mathrm{n}^{\text {os }} 1054$ -

5. Le fond montre en effet la forme bombée caractéristique des gobelets du Centre de la Gaule fabriqués à cette époque. Cf. les productions du "Group 1 ", défini par R.P. Symonds dans son ouvrage Rhenish Wares (1992).
16 et 18), tandis que d'autres ne lui sont que vaguement apparentés (cf. no 1054-17 et 19). Malgré des variations dans l'élaboration de la forme elle-même (tournage) puis de sa finition (lustrage), toutes ces assiettes sont visiblement issues de la même production (pâte sableuse grise, à cœur parfois rougeâtre $)^{6}$, qui ne semble pas être représentée par d'autres modèles de formes communes, lustrées ou non. Sur le plan chronologique, on peut remarquer que ce type est fortement présent dans cet ensemble 1054 datable du courant du $\mathrm{II}^{\mathrm{e}}$ siècle $^{7}$, alors qu'il est pratiquement absent du fossé 2041 , attribuable à la première moitié du III ${ }^{\mathrm{e}}$ siècle (cf. infra, l'étude de cet ensemble). Les contextes découverts à Bretteville-l'Orgueilleuse (fosses 3003 et 2025 : Navarre, 1997) confirment sa circulation durant une bonne partie du II ${ }^{\mathrm{e}}$ siècle, sans toutefois apporter d'élément décisif sur sa probable disparition au $\mathrm{III}^{\mathrm{e}}$ siècle, telle qu'elle est suggérée ici à Saint-Martin-des-Entrées. Ces assiettes sont associées à quelques petits gobelets de silhouettes très semblables ( $4 \mathrm{ex}$. cf. $\mathrm{n}^{\text {os }} 1054-20$ et 21 ). Les exemplaires reconnus sont lisses, dépourvus de toute décoration guillochée ou de dépressions. Mais deux d'entre eux (dont le $\mathrm{n}^{\circ} 1054-21$ ) possèdent une technique rudimentaire de "sablage " de quartz très fin, visant à rappeler grossièrement la décoration très typique des gobelets engobés argonnais. L'observation de l'un des deux vases concernés ( $\left.\mathrm{n}^{\circ} 1054-21\right)$ montre que cette technique s'est faite alors que le gobelet était retourné et posé sur son encolure : toute sa partie inférieure est en effet densément "sablée », tandis que le haut n'a été que peu recouvert. Du point de vue technologique, deux productions peuvent être distinguées, mais l'une d'elles n'est représentée que par un seul exemplaire ( $\left.\mathrm{n}^{\circ} 1054-21\right)$ tandis que l'autre concerne trois exemplaires (dont le $\mathrm{n}^{\circ} 1054-20$ ). Ces deux productions semblent n'avoir aucun lien avec le reste des formes communes lustrées tout en différant aussi apparemment des pâtes communes reconnues dans cet ensemble. En raison de la chronologie des parois fines engobées qu'ils imitent, ces gobelets lustrés ne sauraient être antérieurs au milieu du II $^{\mathrm{e}}$ siècle. Leur absence d'un ensemble comme la fosse 3003 de Bretteville-l'Orgueilleuse, datable de la première moitié du II ${ }^{\mathrm{e}}$ siècle (Navarre, 1997), mais leur présence dans des ensembles situés après le milieu du II $^{\mathrm{e}}$ siècle, comme à Ifs (Feret, 2005, St. 153) appuient cette appréciation. À noter qu'ils semblent disparaître au cours de la première moitié du III $^{\mathrm{e}}$ siècle, comme le suggère leur absence du fossé 2041. Le reste des formes lustrées associées est constitué de quatre formes de poteries différentes, dont trois ont pu être figurées. La plus caractéristique est une forme de pot

6. Une forme tout à fait semblable à ce type d'assiette lustrée, mais en pâte claire, a néanmoins été découverte dans une autre structure du site.

7. Ainsi que dans un certain nombre d'autres contextes découverts sur le site dont le fossé 1071, parfaitement contemporain. 


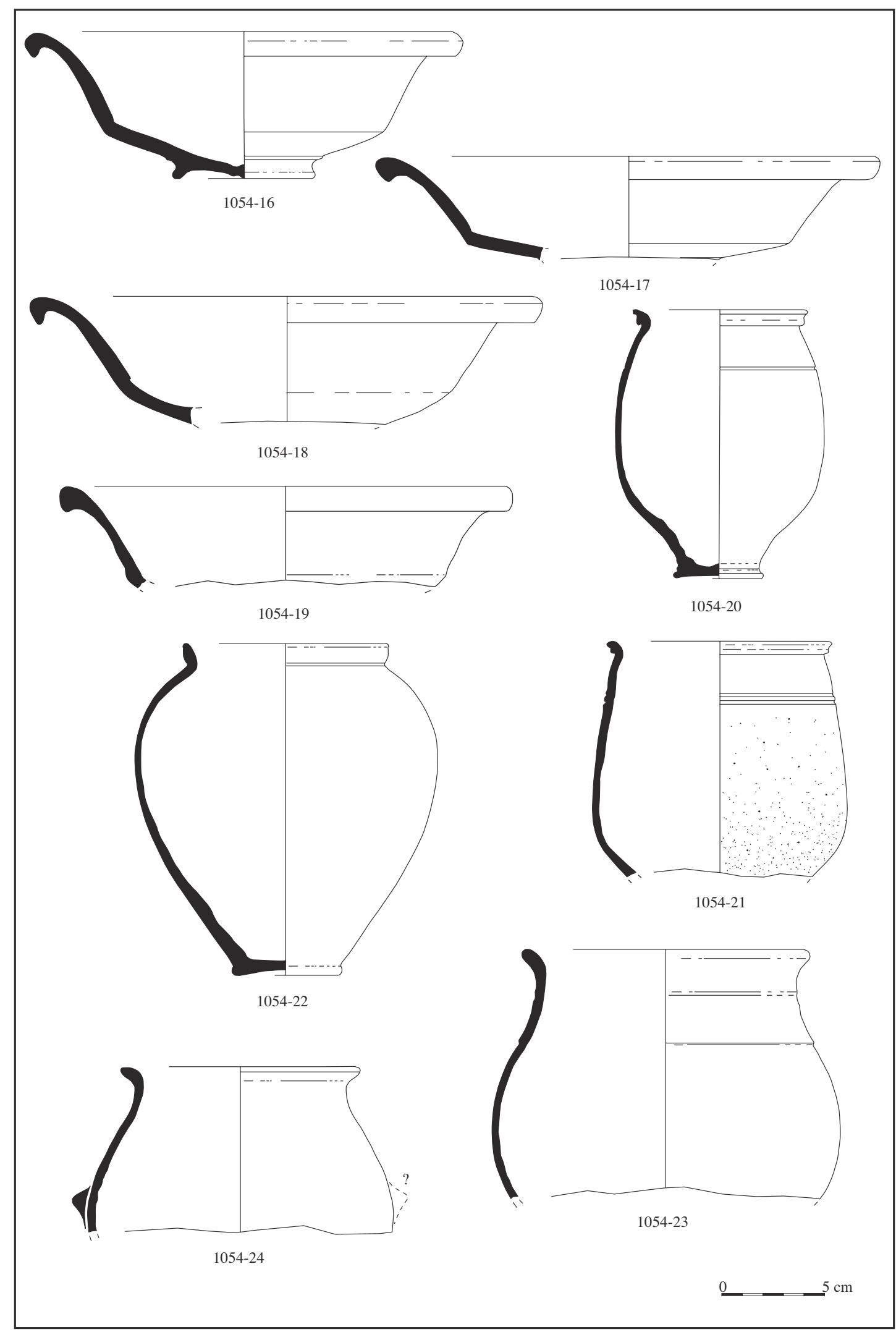

Figure 20 : Saint-Martin-des-Entrées : céramique commune lustrée du fossé 1054 (courant du II ${ }^{\mathrm{e}}$ siècle). Figure 20: Saint-Martin-des-Entrées: Polished common pottery from pit 1054 (2 ${ }^{\text {nd }}$ century). 
ou de grand " gobelet » ovoïde (cf. n ${ }^{\circ}$ 1054-22), dont la silhouette est bien connue, étant notamment à rapprocher d'une forme en Terra Nigra (type Ménez 146). Très bien conservée, cette poterie est pourtant sans aucun doute l'une des plus anciennes de cet ensemble 1054 : elle trouve en effet de parfaites comparaisons pour la deuxième moitié du I ${ }^{\text {er }}$ siècle (cf. St. 1080) ou la première moitié du $\mathrm{II}^{\mathrm{e}}$ siècle (fosse 3003 de Bretteville-l'Orgueilleuse, déjà cité). Elle est d'ailleurs absente d'un ensemble parfaitement contemporain de ce fossé 1054, le fossé 1071 (non présenté). Deux formes inhabituelles complètent cet éventail; il s'agit de pots ou de gobelets entièrement lustrés (cf. ${ }^{\text {os }} 1054-23$ et 24) dont l'un possède un décor de pastille(s) rapportée(s) ( $\left.{ }^{\circ} 1054-24\right)$. Visiblement issus de la même production (pâte entièrement grise, assez fine), ces deux vases ne trouvent actuellement aucune comparaison.

\section{La céramique commune (fig. 21 à 23)}

Elle constitue un ensemble particulièrement conséquent d'au moins 147 poteries qui révèlent la prépondérance de quelques types de formes, et plus particulièrement de l'un d'entre eux, en association avec plusieurs autres types, très inégalement représentés. Les plus nombreux sont les pots à cuire qui regroupent un certain nombre de formes plus ou moins différentes (au moins 46 formes, tous modèles confondus). Dans le détail, cette gamme de poteries peut être globalement divisée en deux groupes distincts :

- les gros pots ou marmites (30 ex.) qui constituent un groupe très homogène malgré des variations de tailles et de formes plus ou moins significatives ainsi que la présence épisodique d'un décor ondé incisé avant cuisson (cf. $\mathrm{n}^{\text {os }} 1054-$ 25 à 34);

- le reste des pots qui rassemble des vases plus diversifiés et de tailles beaucoup plus réduites ( 15 individus, $\mathrm{cf.} \mathrm{n}^{\text {os }} 1054$ 32 et 36 à 40).

Cette distinction typologique correspond à une différenciation technologique (et peut-être aussi fonctionnelle) : en effet, les gros pots ou marmites semblent issus de la même production, ou presque, tandis que les autres variantes de pots laissent apparaître plusieurs provenances. La plupart possède néanmoins le même genre de pâte grossière entièrement réduite, évoquant pour certaines, la technologie des pâtes " granuleuses » connues durant l'Antiquité tardive dans certaines régions limitrophes. Loin d'être le signe d'une technologie rudimentaire ou bien de la contrainte des gisements argileux riches en impuretés, ce type de pâte grossière ou granuleuse paraît plutôt être le fruit d'une technique délibérée permettant de cuire les vases à plus haute température lors de leur fabrication, conférant ainsi une meilleure étanchéité et une meilleure résistance lors de l'utilisation. L'état de cuisson important est d'ailleurs démontré par des déformations observées sur le corps de plusieurs poteries (dont le pot $\mathrm{n}^{\circ}$ 1054-34). Malgré ces accidents de fabrication qui auraient pu provoquer leur mise au rebut, les poteries concernées ont pourtant été commercialisées, confirmant ainsi un phénomène initialement observé à Brettevillel'Orgueilleuse (et notamment dans le fossé 2025; Navarre, 1997). Dotés de parois souvent massives, ces gros pots semblent avoir été avant toute chose des vases à cuire, et notamment à faire bouillir l'eau, comme en témoignent les dépôts calcaires sur les parois internes d'un certain nombre d'exemplaires (dont les $n^{\text {os }} 1054-26,27,28$ et 29). Quelques autres (dont le $\left.\mathrm{n}^{\circ} 1054-30\right)$ présentent des restes (alimentaires?) calcinés sur les parois internes, montrant leur usage pour la cuisson des aliments. Si les pots précédemment décrits constituent un groupe homogène et conséquent au sein de la céramique commune de cet ensemble 1054 comme dans les autres ensembles découverts sur le site ainsi qu’à Brettevillel'Orgueilleuse, ils sont associés à plusieurs autres formes de pots à cuire qui révèlent des silhouettes nettement différentes et surtout plus variées. Les plus explicites de cette diversité sont les formes $\mathrm{n}^{\text {os }} 1054-35$ à 40 , souvent très fragmentées, bien que l'un de ces pots soit presque entier ( $\left.\mathrm{n}^{\circ} 1054-40\right)$. Ce dernier possède comme particularité une taille réduite inhabituelle qui suggère un usage autre que la cuisson; il ne montre d'ailleurs aucune trace de feu. Malgré ces caractéristiques, ce pot ne nous paraît pas être un vase miniature à vocation cultuelle ${ }^{8}$. Les exemples de petites poteries sont en effet relativement fréquents sur les sites d'habitats, sans pour autant que cela induise un usage religieux. Ces pots de formes diverses appartiennent à plusieurs productions : deux sont de type granuleuse ( $\mathrm{n}^{\text {os }} 1054-39$ et 40 ) comme les gros pots et marmites, tandis que les autres sont simplement grossières ou sableuses. Au moins l'une de ces pâtes est aussi attestée avec une écuelle à profil en " $S$ " (cf. $\mathrm{n}^{\circ}$ 1054-42). Après la gamme des pots à cuire, les formes communes les plus représentées dans cet ensemble 1054 sont les mortiers, dont au moins dix exemplaires ont pu être dénombrés avec certitude ( 4 ex. sont illustrés; $c f . n^{\text {os }} 1054-$ 54 à 58). Tous possèdent comme particularité une couleur sombre, le plus souvent entièrement grise mais parfois presque noire ( $\left.\mathrm{n}^{\circ} 1054-58\right)$, qui n'a rien à voir avec le fruit d'une calcination liée à l'utilisation mais qui traduit une cuisson en atmosphère réductrice lors de leur fabrication. Ce mode de cuisson apparaitt très inhabituel pour cet ustensile étroitement lié au mode culinaire romain : en effet, la couleur claire, qui fait référence aux modèles italiques, a ici été délaissée pour la couleur sombre habituelle des poteries culinaires. Si leur couleur apparait donc comme une réelle

8. Par référence à certains exemples de vases trouvés en contexte religieux. 


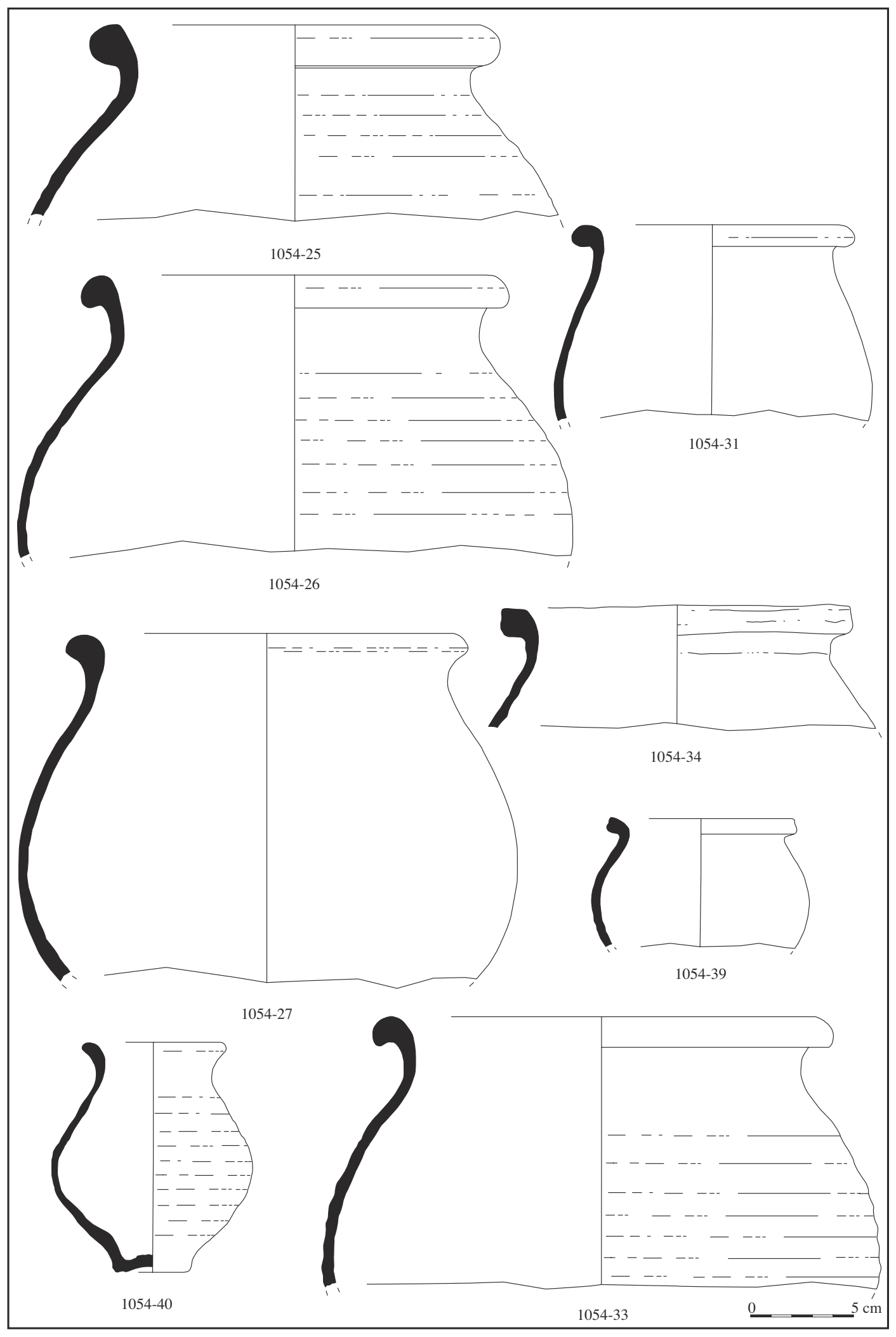

Figure 21 : Saint-Martin-des-Entrées : principales variantes de formes hautes en céramique commune sombre du fossé 1054 (courant du II $^{\mathrm{e}}$ siècle).

Figure 21: Saint-Martin-des-Entrées: main closed forms in common dark ware pottery from pit 1054 (2 $2^{\text {nd }}$ century). 


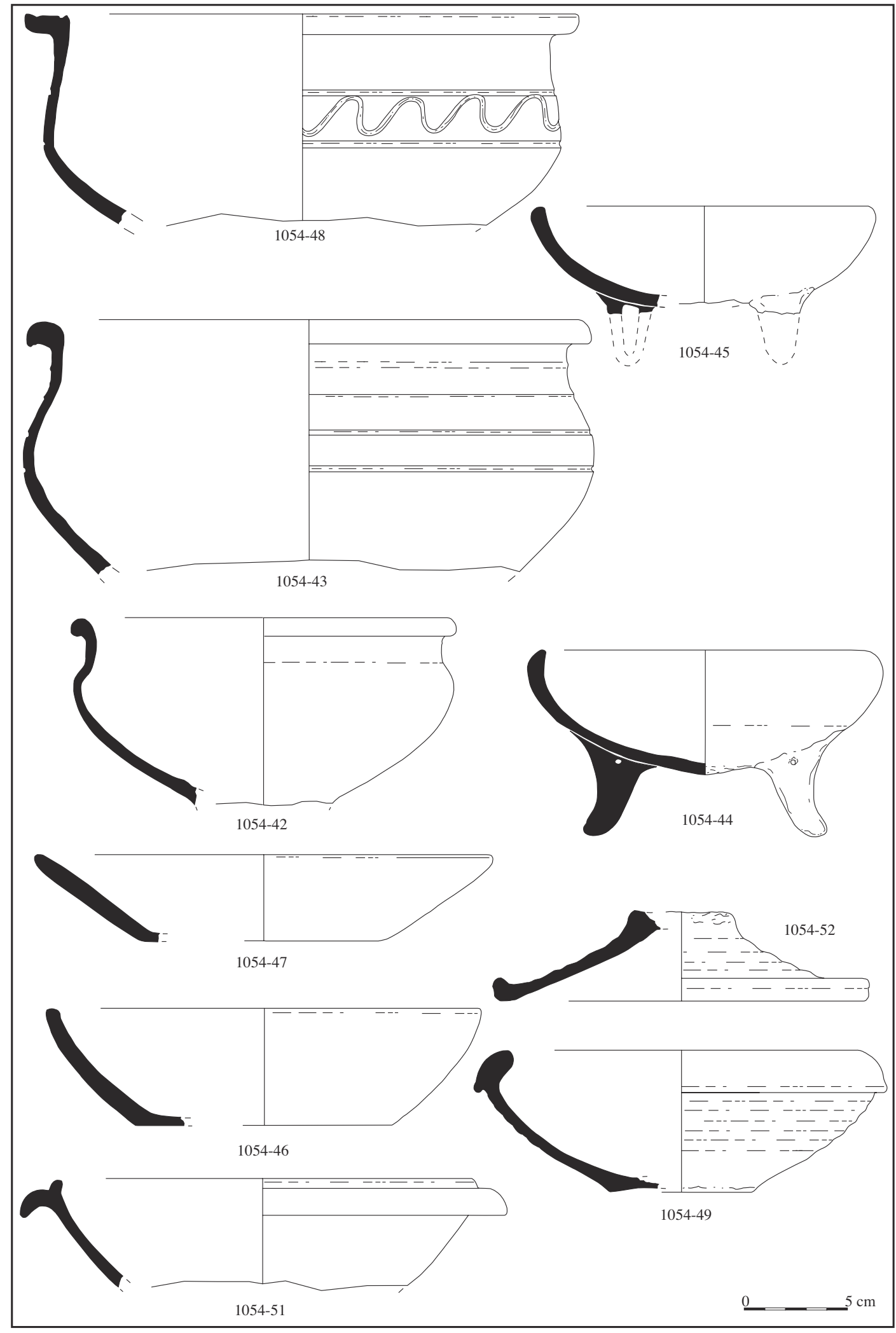

Figure 22 : Saint-Martin-des-Entrées : éventail des formes basses en céramique commune sombre du fossé 1054 (courant du II ${ }^{\mathrm{e}}$ siècle).

Figure 22: Saint-Martin-des-Entrées: range of low forms in common dark ware pottery from pit 1054 (2 $2^{\text {nd }}$ century). 
280

Laurent PAEZ-ReZENDE, Yves-Marie AdRIAN

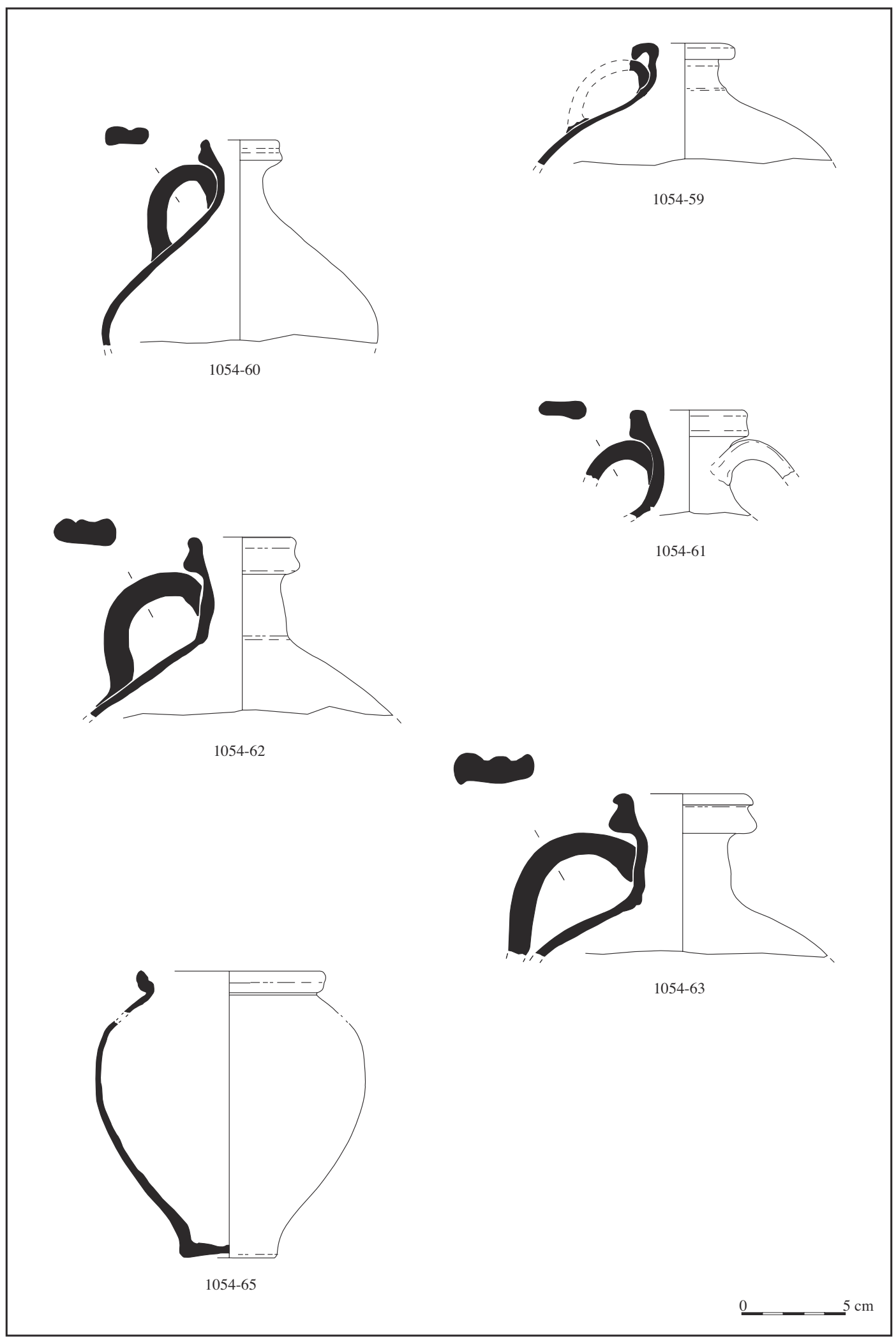

Figure 23 : Saint-Martin-des-Entrées : crushes et pot en céramique commune claire du fosse 1054 (courant du II ${ }^{\mathrm{e}}$ siècle).

Figure 23: Saint-Martin-des-Entrées: jugs and pots in common light ware pottery from pit 1054 (2 $2^{\text {nd }}$ century). 
originalité, la silhouette de ces mortiers est par contre, dans l'ensemble, classique de l'époque, malgré des variantes plus ou moins prononcées et une forme inhabituelle de rebord pour un exemplaire $\left(\mathrm{n}^{\circ} 1054-54\right)$. On remarque que ces formes n'ont rien de commun avec celles du $\mathrm{I}^{\mathrm{er}}$ siècle. À une ou deux exceptions près (dont le $\left.\mathrm{n}^{\circ} 1054-58\right)$, tous ces mortiers semblent issus de la même production qui pourrait bien correspondre à la production granuleuse fortement représentée au sein des gros pots à cuire ou marmites, ainsi qu'avec un certain nombre d'autres formes de cet ensemble. Cette production de mortiers est celle rencontrée à Brettevillel'Orgueilleuse (Navarre, 1997), sans pourtant que son mode de cuisson spécifique n'y ait été réellement mis en avant alors qu'il correspond à une véritable spécificité, sans équivalent dans les territoires environnants. Après les mortiers, les poteries communes sombres les plus nombreuses de cet ensemble sont des formes basses et ouvertes de différents modèles. Les dépôts plus ou moins significatifs de suie ainsi que les décolorations observées mettent en évidence leur usage pour la cuisson des aliments. Cette catégorie regroupe quatre types très différents et inégalement distribués :

- formes à profil « $S$ » (6 exemplaires assez similaires, cf. $\mathrm{n}^{\text {os }} 1054-41$ à 43$)$;

- formes tripodes " hémisphériques » (6 exemplaires identiques, cf. $\mathrm{n}^{\text {os }} 1054-44$ et 45 );

- formes à bords évasés ou "plats» (5 exemplaires plus ou moins indéterminés; $c f . n^{\text {os }} 1054-46$ et 47 );

- forme presque carénée à décor incisé ondé (1 ex. cf. $\left.\mathrm{n}^{\circ} 1054-48\right)$.

Les formes à profil en « $S$ » sont les successeurs directs des modèles du $\mathrm{I}^{\mathrm{er}}$ siècle. Certaines (dont les $\mathrm{n}^{\text {os }} 1054-41$ et 42 ) sont même très proches des exemplaires de cette époque. La différence majeure avec les séries antérieures réside en réalité dans les techniques de fabrication : les quelques productions en présence n'ont en effet rien à voir avec celles observées dans un ensemble comme la fosse 1080, datable de la deuxième moitié du $\mathrm{I}^{\text {er }}$ siècle (cf. supra, l'étude de cet ensemble). Elles sont en outre très ponctuellement représentées : si quelques-unes (dont celle de l'écuelle no 1054-42) sont aussi attestées avec quelques pots à cuire, d'autres semblent seulement attestées avec un seul exemplaire de ce type, traduisant sans doute des approvisionnements ponctuels.

Par leur silhouette très caractéristique, presque « hémisphérique ", les poteries tripodes constituent un type homogène malgré quelques variations dans la fabrication des pieds : en effet, certains sont pleins, réalisés à partir de petits boudins de pâtes façonnés à la main et pour l'occasion percés d'un trou latéral ${ }^{9}$ (cf. le no 1054-44) tandis que d'autres

9. Cette technique visait à éviter leur décollement lors de la cuisson, en permettant à l'air présent à l'intérieur du pied de s'évacuer lors de la cuisson. pieds sont creux et ont été réalisés au tour (cf. nº 1054-45). Il s'agit par contre dans tous les cas de longs pieds plus ou moins pointus et courbés, presque démesurés par rapport à la taille somme toute réduite des récipients. Observée sur quelques exemplaires (dont le $\mathrm{n}^{\circ}$ 1054-44), la courbure du pied pourrait être le résultat d'un affaissement intervenu après application de pieds trop humides ou bien lors de l'empilement des poteries lors de leur séchage. Mais on ne peut exclure qu'il s'agisse d'un dispositif volontaire destiné à améliorer la stabilité des vases.

Les écuelles à " bords évasés " présentent d'évidentes ressemblances avec les plats habituellement rencontrés aux II ${ }^{\mathrm{e}}$ et III $^{\text {e }}$ siècles dans une bonne partie de la Gaule. Mais les exemplaires reconnus ici s'en différencient soit par un bord particulièrement haut (cf. le $\mathrm{n}^{\circ} 1054-46$ ), soit étonnement évasé (cf. le no ${ }^{\circ}$ 1054-47). Cette différence d'ouverture coïncide avec deux provenances distinctes et uniques au sein de cet ensemble 1054.

Unique, la forme carénée à décor ondé $n^{\circ} 1054-48$ correspond vraisemblablement à une forme " ancienne " au sein de cet ensemble : elle ne trouve en effet aucun équivalent dans les nombreux autres ensembles du II $^{\mathrm{e}}$ siècle découverts sur le site tandis qu'un exemplaire assez semblable, mais non décoré, est attesté dans un contexte datable de la fin du I ${ }^{\text {er }}$ début du $\mathrm{II}^{\mathrm{e}}$ siècle $^{10}$. Elle participe sans doute, avec quelques poteries communes ou sigillées, au fond ancien observé dans cet ensemble, qui pourrait en fait représenter les tout premiers rejets déversés dans ce fossé.

Plusieurs couvercles complètent cet éventail de poteries destinées à la cuisson des aliments ( 2 ex. illustrés, cf. $\mathrm{n}^{\text {os }} 1054-52$ et 53 ). Ils présentent tous le même type de bord pouvant s'adapter à diverses formes, qu' elles soient de type pot ou bien de type écuelle. Si les pâtes observées sur cet ustensile reflètent bien la tendance générale de la céramique commune de cet ensemble, à savoir une certaine diversité, au moins deux d'entre eux (dont le $\mathrm{n}^{\circ}$ 1054-53) appartiennent aux mêmes productions granuleuses que les gros pots ou marmites, et peut-être aussi que les mortiers.

Enfin, quelques formes ouvertes très différentes, que nous avons dénommées jattes, clôturent l'éventail des poteries sombres (cf. $\mathrm{n}^{\text {os }} 1054-49,50$ et 51 ). Il s'agit peut-être de poteries destinées au service et à la consommation des aliments : elles ne présentent en effet aucune calcination en rapport avec une exposition à la chaleur d'un foyer, mais plutôt, pour au moins deux d'entre elles ( $\mathrm{n}^{\text {os }} 1054-49$ et 51) des traces importantes de "frottement " dans la partie inférieure, qui diffère cependant de l'usure liée au broyage telle que l'on peut l'observer à l'intérieur des mortiers. L'une d'entre elles ( $\left.n^{\circ} 1054-49\right)$ appartient à la même pro-

10. Fossé 1091, non présenté. 
duction "granuleuse " que les gros pots ou marmites et peut-être aussi que les mortiers. Attesté ici avec au moins deux exemplaires, ce type de « jatte » trouve un proche parallèle avec ceux découverts à Bretteville-l'Orgueilleuse dans des contextes de la première moitié du II $^{\mathrm{e}}$ siècle (St. III et fosse 3003 : Navarre 1996 et 1997).

\section{Les céramiques à pâtes claires}

Elles concernent presque exclusivement les cruches qui ont comme principale caractéristique une grande homogénéité morphologique, évoquant quasiment une sorte de «standardisation ", couplée à une faible variété technologique et donc aussi visiblement de provenances, tout au plus au nombre de deux. Les pâtes, tendres car peu cuites, sont majoritairement oranges, parfois beiges. Elles correspondent manifestement à celles signalées à Bretteville-l'Orgueilleuse ou encore dans l'Orne ${ }^{11}$ et dont la diffusion est par ailleurs importante vers l'est du territoire normand (Eure). Pas moins de 19 exemplaires très semblables ont pu être ici dénombrés (cinq sont illustrés; cf. nos 1054-60 à 64), associés à un autre modèle, très différent, tant par sa forme que sa pâte ( $\mathrm{n}^{\circ}$ 1054-59). Ces 19 exemplaires ne se distinguent que par des tailles différentes ou bien par quelques détails dans l'élaboration du col. Seule l'une d'entre elles ( $\left.\mathrm{n}^{\circ} 1054-61\right)$ possédait deux anses. Pour augmenter leur étanchéité, quelques-unes de ces cruches ont été intérieurement enduites d'un revêtement noirâtre, probablement résineux ou poisseux (dont la cruche $\mathrm{n}^{\circ}$ 1054-60). Un unique petit pot ferme le faible éventail de poteries en pâtes claires ( $\left.\mathrm{n}^{\circ} 1054-65\right)$. Doté d'une pâte orangée, ce pot apparaît comme une autre forme ancienne de cet ensemble 1054 : sa forme et sa technologie très particulières trouvent en effet de nombreuses comparaisons pour le $\mathrm{I}^{\text {er }}$ siècle, notamment dans la fosse 1080 (cf. supra), voire le début du $\mathrm{II}^{\mathrm{e}}$ siècle $^{12}$. Mais il est peu probable que ce type ait été encore fabriqué et utilisé à une date assez avancée dans le $\mathrm{II}^{\mathrm{e}}$ siècle, telle qu'elle nous est fournie pas le lot conséquent de sigillées. Cette appréciation trouve en outre confirmation dans quelques autres ensembles du $\mathrm{II}^{\mathrm{e}}$ siècle découverts sur le site $^{13}$, dans lesquels ce type est absent.

\section{Chronologie de l'ensemble 1054}

Le volume conséquent de sigillées et leurs caractéristiques fournissent un repère très précis pour une datation ultime durant le troisième quart $\mathrm{du} \mathrm{II}^{\mathrm{e}}$ siècle, soit entre les années 160 et 170-175. Les comparaisons disponibles avec les autres ensembles régionaux, que ce soient ceux de Bretteville-l'Orgueilleuse (Navarre, 1997), d'Ifs (Féret,

11. Information orale de L. Simon (INRAP), à l'occasion de son étude du site du Mesnil-Froger.

12. Fossé 1081, non présenté.

13. Dont le fossé 1071, parfaitement contemporain de 1054.
2005) ou Fleury-sur-Orne (Mortreau et Adrian, 2002), confirment cette datation pour le courant du $\mathrm{II}^{\mathrm{e}}$ siècle. Mais ces comparaisons mettent parallèlement en évidence la présence de ce que l'on peut appeler un fond ancien. Celui-ci rassemble quelques poteries (nous les évaluons à six ou huit), sigillées, sans doute une paroi fine engobée, et plusieurs céramiques communes, qui, sans réellement constituer un résidu de tessons épars ayant été transportés dans des remblais, représentent probablement les premiers rejets basculés dans ce fossé, à une date que l'on peut situer durant la première moitié du $\mathrm{II}^{\mathrm{e}}$ siècle. Si ces formes anciennes, comme la coupe sigillée Drag. 36 de La Graufesenque, un Drag. 38 de Lezoux et le gobelet à paroi fine engobée du centre de la Gaule peuvent bien servir de repère chronologique, il est alors peut-être possible d'évaluer la durée de la formation de ce dépotoir à une quarantaine d'années. Ainsi constitué, cet ensemble 1054 apparaît chronologiquement intercalé entre la fosse 3003 de Bretteville-l'Orgueilleuse, attribuée à la première moitié du II $^{\mathrm{e}}$ siècle, et le fossé 2025 de ce même site, daté de la fin du II ${ }^{\mathrm{e}}$ siècle - et la première moitié du III siècle (Navarre, 1997). Il s'agit donc d'une référence complémentaire qui permet une vision continue de l'évolution du répertoire tout au long du $\mathrm{II}^{\mathrm{e}}$ siècle.

\section{L'abandon du sanctuaire à la fin du $\mathrm{II}^{\mathrm{e}}$ siècle}

À l'intérieur ou autour du sanctuaire, il n'existe aucun élément céramique, ni autre mobilier, permettant d'illustrer une fréquentation au-delà de la fin du $\mathrm{II}^{\mathrm{e}}$ siècle. L'occupation plus tardive dans le III $^{\mathrm{e}}$ siècle est représentée par un seul fossé de parcellaire relativement distant puisque située à 200 mètres à l'est de l'ensemble religieux. Il manifeste à l'évidence les ultimes avatars de l'établissement rural dans un secteur où la désaffection des structures agraires semble déjà active à la fin du $\mathrm{II}^{\mathrm{e}}$ siècle.

\section{Les grandes tendances du répertoire céramique}

Le répertoire rencontré à Saint-Martin-des-Entrées présente, sans surprise, une forte parenté avec celui reconnu sur d'autres sites voisins, tel Bretteville-l'Orgueilleuse distant d'une vingtaine de kilomètres. Dans le détail, si un certain nombre de similitudes dans les formes et certainement aussi dans les productions tendent à les rapprocher, quelques absences ou différences significatives méritent pourtant d'être soulignées : le trait le plus notoire concerne sans aucun doute la céramique non tournée, totalement absente à Saint-Martin-des-Entrées ${ }^{14}$ alors qu'elle semble bien attestée à Bretteville-l'Orgueilleuse durant tout le Haut-Empire,

14. Cette absence est-elle en rapport avec la nature cultuelle du site? 
y compris jusqu'au III siècle (Navarre, 1997). De même, le répertoire de la céramique commune sombre révèle plusieurs différences qui peuvent facilement être perçues aux travers des illustrations graphiques des ensembles respectifs.

De manière générale, ce répertoire semble montrer des degrés variables de parentés suivant les époques, avec les répertoires voisins, tout au moins ceux que nous connaissons. C'est sans doute durant la première moitié du II $^{\mathrm{e}}$ siècle qu'un répertoire réellement " local " semble se distinguer en créant certains types spécifiques ou en adaptant certains modèles connus ailleurs. Ce particularisme transparaît surtout avec l'importante gamme de pots à cuire ou marmites, issue principalement d'un même groupe de pâtes, ainsi qu'avec plusieurs autres formes comme les mortiers à cuisson réductrice qui apparaissent comme une réelle originalité de ce territoire. La diffusion de mortiers en pâte grise grossière semble n'avoir pratiquement pas concerné les territoires voisins : elle est ainsi ponctuellement attestée dans les îles Anglo-Normandes, à Guernesey ${ }^{15}$, ainsi que jusque dans la région d'Évreux $(\text { Eure })^{16}$, tout en étant apparemment moins significative en plaine de Caen (Ifs : Ferret, 2005) ${ }^{17}$. Mais ces quelques diffusions éloignées, très restreintes, traduisent sans doute des acheminements ponctuels liés à des approvisionnements ou à des déplacements limités. Par la même occasion, elles témoignent pourtant de la facilité de circulation d'objets très courants, sans toutefois remettre en cause l'idée d'un réel particularisme local.

Le développement d'un répertoire assez spécifique paraît se confirmer dans le courant du II $^{\mathrm{e}}$ siècle et se poursuivre jusqu'au $\mathrm{III}^{\mathrm{e}}$ siècle, au moins. Les ensembles, comme ceux des fossés 1054 et 2041 de Saint-Martin-des-Entrées, ou le fossé 2025 de Bretteville-l'Orgueilleuse n'ont en effet que peu de points communs, voire aucun, avec ceux des autres territoires, qu'ils soient proches comme à Vieux (Jardel, 2002) ou plus éloignés comme ceux de l'actuelle Haute-Normandie par exemple, ou encore dans l'Orne (Leclerc, 2007 et 2008). Ces productions particulières, principalement des pots à cuire mais aussi des gobelets lustrés, sont néanmoins ponctuées de formes plus répandues, parfois adaptées par l'artisanat local : si le modèle des cruches en pâtes claires s'avère ainsi parfaitement identique, évoquant quasiment une standardisation, celui de l'écuelle hémisphérique tripode présente quelques particularités qui montrent sa reprise par un ou plusieurs ate-

15. Cf. l'inventaire de l'épave de "Saint Peter Port " (Monaghan, 1987). Mais cette épave dans laquelle a été trouvée un mortier réduit de forme tout à fait semblable à nos exemplaires, est attribuée à la fin du III ${ }^{\mathrm{e}}$ siècle.

16. Site rural de Guichainville "Le Devant de la Garenne " (fouille P. Flotté, 1996-1997; étude de l'auteur). Ce site a livré un unique exemplaire de mortier réduit parfaitement identique à ces exemplaires de Saint-Martindes-Entrées. Sa provenance du « Bessin » semble ne faire aucun doute.

17. Les mortiers réduits sont ainsi absents du site de Rots, «Cap Ouest " (fouille de V. Carpentier, 1994). liers régionaux ayant adapté sa production à leurs contraintes ou bien à leurs habitudes de fabrication.

Cette association de formes spécifiques à un territoire, avec des formes très largement répandues, n'est toutefois pas un cas isolé : elle caractérise aussi les répertoires potiers situés plus à l'est, chez les Lexovii ou bien chez les Aulerques Eburovices qui semblent avoir eux aussi repris à leurs comptes un ou deux modèles courants, peut-être "à la mode ", tout en offrant sur le marché des formes particulières plus ou moins variées et " originales " dont la diffusion plus ou moins forte tend à dessiner ce que l'on peut appeler un faciès.

Les différentes pâtes de la céramique commune offrent le visage d'une grande diversité technologique mais variable suivant les époques. Loin d'être uniforme, la production locale ou bien celle qui a été diffusée localement apparaît ainsi avoir connu des renouvellements périodiques en rapport avec des provenances différentes qui ont à l'évidence été assez variées.

$A u \mathrm{I}^{\mathrm{er}}$ siècle, et plus précisément durant la deuxième moitié, au moins une douzaine de pâtes se distinguent parmi les poteries communes découvertes dans la fosse 1080, évoquant des productions distinctes mais qui semblent inégalement représentées. Certaines sont en effet présentes avec plusieurs types de formes (pots, écuelles, assiettes), et parfois en plusieurs exemplaires de chaque, tandis que d'autres n'apparaissent attestées qu'avec une voire deux poteries seulement. Cette inégale représentation semble traduire l'association d'approvisionnements réguliers auprès d'un ou de quelques ateliers de proximité, avec des approvisionnements ponctuels auprès d'ateliers peut-être plus éloignés, qu'ils soient liés à des acheminements irréguliers de la part de potiers ou de négociants ou bien aux déplacements occasionnels de consommateurs. Mais il n'est pas exclu qu'elle traduise dans certains cas aussi des niveaux de productions, certains ateliers produisant plus et diffusant plus loin que d'autres.

Un phénomène assez comparable apparaît dans les ensembles du $\mathrm{II}^{\mathrm{e}}$ siècle, puis du $\mathrm{III}^{\mathrm{e}}$ siècle, mais dans une bien moindre mesure : en effet, si un ensemble comme le fossé 1054 révèle apparemment une grande diversité de pâtes (pas moins d'une quinzaine de productions semble se distinguer), un groupe de pâtes/productions, les granuleuses, domine en réalité très nettement durant une bonne partie du $\mathrm{II}^{\mathrm{e}}$ siècle. Ce groupe est présent essentiellement avec des gros pots à cuire ou marmites, accompagnées de quelques formes diverses, petits pots, jattes, couvercles, auxquelles il faudrait sans doute aussi associer les mortiers à cuisson réductrice ${ }^{18}$.

18. Sans être à proprement parler granuleuses ou aussi riches en dégraissant, les pâtes de ces mortiers présentent un bon nombre de similitudes, notamment d'ordre minéralogique (d'après examen à la loupe binoculaire). 
Associé à ce groupe dominant, un certain nombre de productions très différentes peuvent être reconnues au cours $\mathrm{du} \mathrm{II}^{\mathrm{e}}$ siècle : certaines ne sont que très ponctuellement représentées, avec deux ou trois modèles différents, tandis que d'autres le sont avec seulement un seul, qui plus est en un unique exemplaire. Plus qu'au $\mathrm{I}^{\mathrm{er}}$ siècle, ces différences très importantes de proportions semblent traduire l'association d'une source principale d'approvisionnement locale ou régionale (le groupe des pâtes granuleuses), avec plusieurs autres, dont une part est sans doute elle aussi d'origine(s) locale(s), sans exclure quelques approvisionnements de plus longues distances, impliquant des ateliers éloignés.

Seul ensemble du III $^{\mathrm{e}}$ siècle découvert sur le site, le fossé 2041 révèle lui aussi une importante diversité de productions, sans pourtant montrer la même domination d'un type particulier de pâte(s) qu'au siècle précédent (fossé 1054). En effet, si le groupe des pâtes " granuleuses " est encore présent à cette époque, il ne représente visiblement plus qu'une petite partie des approvisionnements face à des productions diverses dont une bonne part semble totalement nouvelle par rapport aux productions antérieures. Il semble évident qu'il y ait eu un certain renouvellement de la céramique commune sombre, à une époque que l'on pourrait situer, en utilisant aussi les données fournies par les quelques exemples régionaux disponibles, vers le début du III ${ }^{\mathrm{e}}$ siècle. À l'inverse, les céramiques à pâtes claires ne semblent pas avoir changées : les formes et les pâtes sont identiques entre le courant $\mathrm{du} \mathrm{II}^{\mathrm{e}}$ et la première moitié du III ${ }^{\mathrm{e}}$ siècle.

Mais si les productions de la première moitié du $\mathrm{III}^{\mathrm{e}}$ siècle semblent, pour une bonne part, différentes de celles du $\mathrm{II}^{\mathrm{e}}$ siècle, leurs caractéristiques technologiques laissent penser qu'elles appartiennent au même faciès géologique. Le caractère local de la plupart d'entre elles semble donc ne faire aucun doute, mais l'absence de comparaisons concrètes dans l'environnement régional ne nous permet pas aujourd'hui d'en dire beaucoup plus.

\section{Conclusion}

À plusieurs égards, le sanctuaire de Saint-Martin-desEntrées se démarque des sites cultuels les plus couramment rencontrés en Gaule romaine, non pas sur le plan de sa configuration générale, qui reste au contraire très traditionnelle dans ses principaux équipements (péribole, temple, édicule, portique et peut-être même favissa), mais plutôt sur les modes de construction de chacun de ses éléments. Il interroge également sur le statut, le cadre de son évolution et le caractère non spécifique des mobiliers déposés, et particulièrement la céramique. En effet, les rites pratiqués sur le site de Saint-Martin-des-Entrées n'ont apparemment pas mis en œuvre de façon particulière des vases et ne semblent pas non plus avoir connu des libations utilisant des types de poteries spécifiques comme des coupes ou des assiettes, des patères, des cruches ou encore des oenochoe. Si plusieurs poteries ont pu être identifiées comme des offrandes, particulièrement dans le fossé 1023, elles restent limitées à quelques céramiques communes ordinaires, associées à des dépôts de boucherie qui suggèrent la tenue de banquets.

\section{L'utilisation des céramiques}

Dans le détail, la céramique découverte ne revêt aucun caractère exceptionnel, autant dans sa composition typologique que fonctionnelle. Les volumes assez importants de certains ensembles trouvent, en outre, des comparaisons sur des habitats de la même époque ou bien dans les régions voisines. La comparaison du mobilier céramique découvert ici avec celui provenant d'un certain nombre de sanctuaires fouillés en Gaule, contredit l'idée de dépôts mobiliers hors du commun : plus que de véritables offrandes de vases, en groupes comme à Alésia (Rabeisen, 1994), ou bien enterrés un à un devant l'esplanade comme à Saint-Martin-de-Boscherville, non loin de Rouen (Le Maho, 1994 et 1998). Les débris de quelques poteries ont bien été découverts ici et là devant la cella, mais leur dépôt volontaire est loin d'être évident et n'a rien de comparable avec les exemples cités. Ainsi les poteries découvertes à Saint-Martin-des-Entrées ne peuvent être distinguées des céramiques ordinaires en rejets après une utilisation domestique. Aucune anomalie particulière n'a en effet été décelée : un seul vase miniature et un seul grafitto: une petite coupelle en sigillée découverte dans le fossé 1054 a révélé une lettre isolée (initiale?), gravée sur la panse, mais on est loin des multiples exemplaires gravés découverts à Guichainville, près d'Évreux, par exemple (Adrian, 2001); absence de vase particulièrement neuf; absence de mutilation ou de traitement spécifique des vases (trous), de proportion inhabituelle de céramiques fines ou d'un type particulier de poterie, comme les cruches, par exemple. Certes, il y a bien quelques poteries montrant des parties qui pourraient avoir été volontairement enlevées, comme un pot découvert presque entier dans le fossé 1092 (non présenté) et dépourvu de son fond, ou un petit gobelet lustré à dépressions provenant du fossé 2041 (cf. l'étude de cet ensemble) et dépourvu de toute son encolure. Mais ces poteries restent très peu nombreuses et réparties dans différents contextes. Elles ne suffisent donc pas à prouver une mutilation spécifique, qui pourrait tout aussi bien correspondre à des pratiques ou des réutilisations domestiques. 
Loin de participer à une évidente pratique cultuelle, les ensembles découverts laissent plutôt apparaître l'éventail complet et habituel du répertoire céramique gallo-romain. Si on peut dès lors suggérer que la céramique ait servi au repas des fidèles fréquentant le sanctuaire, il semble raisonnable de penser qu'elle a été utilisée plusieurs fois, et dans des conditions semblables à l'utilisation domestique habituelle de l'époque : la plupart des écuelles ou des pots à cuire portent ainsi les séquelles de chauffes répétées, certains sont abondamment recouverts de dépôts calcaires à l'intérieur, les mortiers sont usés, parfois très fortement, tandis que les assiettes ou les « jattes " présentent des traces de frottements à l'intérieur. Après usure ou bris non spécifiques, les poteries ont manifestement été jetées pêle-mêle dans des fosses ou des fossés, voire dans un premier temps épandues sur des dépotoirs à ciel ouvert.

Un tel rejet de céramiques utilisées et dispersées dans des fosses et surtout dans des fossés trouve un parfait parallèle au sein d'un sanctuaire rural haut normand implanté dans la région d'Evreux (Eure; Flotté et al., 1997; pour la céramique : Adrian, 2001). Si la céramique découverte sur ce dernier site se distingue par ses volumes importants pour une période relativement courte (à peu près la deuxième moitié du ir siècle), elle ne révèle de même aucune caractéristique anormale dans sa composition ou son mode d'enfouissement (rejets pêle mêle). Plusieurs cas de mutilations et perforations sont toutefois à relever, en particulier sur des vases fermés (pots et surtout cruches dont le fond a été percé).

\section{L'architecture et l'originalité du sanctuaire}

Il rejoint la courte liste des exemples ${ }^{19}$ conservant un péribole uniquement fossoyé durant l'intégralité de son fonctionnement et, ce, malgré son réaménagement. Unique au niveau régional, il ne trouve de plus proche comparaison qu'auprès du sanctuaire d'Hecmanville dans l'Eure (Maret, 2006, p. 52). Dans les autres exemples recensés par I. Fauduet, les périboles fossoyés correspondent souvent à l'état d'origine auquel se substitue très rapidement un mur (Fauduet, 2010, p. 73).

Sur le plan architectural, l'aedes de Saint-Martin se démarque également du plus grand nombre en raison de la pluralité des matériaux employés : ossature de bois pour la galerie, maçonnerie en dur pour les fondations et les élévations ou une partie seulement, auquel cas les matériaux périssables prendraient le relais. À l'exception des orienta-

19. En 1993, l'atlas de Fauduet n'en recensait que 11 sur les 223 sanctuaires à péribole attesté, soit à peine $5 \%$.(Fauduet 1993b, p. 104) et n'en mentionne que "plus d'une vingtaine " en 2010 dans l'édition revue et augmentée (Fauduet 2010, p. 73). tions, il peut être comparé à celui de Versigny dans l'Aisne (Fauduet, 1993b, p. 40). Même si l'emploi de matériaux différents est assez répandu en Gaule (Ibid, p. 126-127), il reste une pratique que seul illustre le sanctuaire de la Pièce des Côtelets à l'échelon régional, mais compte tenu d'un corpus encore peu étoffé, il est trop tôt pour en tirer de quelconques conclusions.

\section{La vocation du sanctuaire}

La proximité des vestiges d'un établissement rural et l'intégration du péribole dans le parcellaire antique militent pour l'appartenance de ce sanctuaire à cet établissement. Pour autant, avec la proximité du chef-lieu de cité des Baïocasses, la question de l'éventualité d'un lieu de culte périurbain (Pechoux, 2011, p. 32-34) ou suburbain est posée. De fait, elle doit être rapidement débattue à la lumière des travaux récents sur la question (Pechoux, 2010 et 2011). Le principal argument tient dans la taille de l'aire sacrée qui, avec ses 4500 mètres carrés initiaux, augmentés à 5600 mètres carrés dans la seconde phase de fonctionnement, propose une surface de rassemblement dans la moyenne de la plupart des grands sanctuaires périurbains, dont les plus grandes fréquences varient entre 1400 à 20000 mètres carrés. L'ampleur de cette aire sacrée et la dissociation entre le sanctuaire et l'établissement rural conduisent à s'interroger sur une utilisation exclusivement réservée à un culte privé ou familial. C'est un cas de figure qui demeure assez rare dans le cadre des villae, où la structure religieuse est le plus souvent intégrée à la pars urbana. À Saint-Martin, l'isolement dans le parcellaire, manifestement à l'écart de l'épicentre de l'établissement rural qui en serait à l'origine, ainsi que la dotation d'un chemin d'accès spécifique, oriente l'interprétation vers un lieu sacré à caractère collectif et sans doute mis à la disposition des populations rurales environnantes.

\section{Bibliographie}

Adrian Y.-M., I996 - Gonneville-sur-Scie, "Terres de la Vatine " (76), Rapport d'étude du mobilier céramique (2 vol.), Afan/ SRA de Haute-Normandie.

Adrian Y.-M., 2000 - Saint-Martin-des-Entrées, "La Pièce des Côtelets" : Le sanctuaire et l'établissement rural gallo-romain - Analyse du site, Document final de synthèse, vol. 2. Caen, non paginé.

Adrian Y.-M., 200 I - "La céramique du Haut-Empire dans la région d'Évreux : première approche du répertoire et des approvisionnements ", Revue archéologique de l'Ouest, $\mathrm{n}^{\circ} 18$, p. $95-143$. 
Brulet R. Vilvorder F. et Delage R., 20 io - La céramique romaine en Gaule du Nord. Dictionnaire des céramiques. La vaisselle à large diffusion, Centre de recherches d'archéologie nationale (Louvain-la-Neuve, Belgique), Turnhout, Brepols, $464 \mathrm{p}$.

Cabuy Y., I994 - "Temples et sanctuaires de tradition indigène en Belgique romaine ", in Goudineau C., Fauduet I. et Coulon G. (dir.), Les sanctuaires de tradition indigène en Gaule romaine, Actes du colloque d'Argentomagus (Argenton-sur-Creuse/ Saint-Marcel, Indre), 8, 9 et 10 octobre 1992, Paris, Errance, coll. "Archéologie aujourd'hui », p. 24-32.

Cuyt G., I 987 - « De bewoning rond Antwerpen tijdens de Galloromeinse periode", in Warmenbol, p. 132-134.

Doranlo R., I 940 - «Les voies antiques de Bayeux à Caudebecen-Caux et à Rouen dans leur traversée du Bessin ", Bulletin de la Société des Antiquaire de Normandie, Tome XCVIII, 1940, p. 547-557.

FAUduet I., I993a - Les temples de tradition celtique en Gaule romaine, Paris, Errance, coll. "Les Hespérides », 160 p.

Fauduet I., I993b - Atlas des sanctuaires romano-celtiques de Gaule. Les fanums, Paris éditions Errance, coll. "Archéologie aujourd'hui ", $160 \mathrm{p}$.

Fauduet I., 2010 - Les temples de tradition celtique en Gaule romaine, Paris, éditions Errance, coll. « Les Hespérides ", nouvelle édition revue et augmentée, $352 \mathrm{p}$.

FÉRET L., 2005 - «Les ensembles céramiques de la Dronnière à Ifs (Calvados), un habitat rural du II ${ }^{\mathrm{e}}$ siècle apr. J-C. en plaine de Caen ", SFECAG, Actes du congrès de Blois, p. 593-608.

Fichet de Clairfontaine F. et Gros H., i 995 - Le mobilier céramique des années 50-80 apr. J.-C. Étude d'un ensemble clos du site de la rue Amesland "SFECAG, Actes du congrès de Rouen, p. 25-37.

Flotte P., LÉon G., Richard J.-M. et Adrian Y.-M., I 997 - Le sanctuaire gallo-romain du Devant-de-la-Garenne et son environnement, Document final de synthèse de fouille, SRA de Haute-Normandie.

Gose E., I950 - Gefässtypen der römischen Keramik im Rheinland. Beihefte der Bonner Jahrbûcher 1, Köln.

Gruel K. et Brouquier-Reddé V., 2003 - Le sanctuaire de Mars Mullo, Allonnes (Sarthe), Le Mans : éditions de la Reinette, $192 \mathrm{p}$.

Hosdez C. et JACQues A., I989 - " La nécropole à incinérations de Baralle (Pas-de-Calais) ", Nord-Ouest Archéologie, nº 2, Berck-sur-Mer : éditions du Centre de recherches archéologiques et de diffusions culturelles (CRADC), $225 \mathrm{p}$.

Lambert E., I 84I - «Procès-verbal du rétablissement de la colonne milliaire, trouvée au manoir, près de Bayeux, en 1819 ", in Mémoires de la Société des antiquaires de Normandie, 12, Caen, p. 405-409.

LeClerC G., 2007 - "Le sanctuaire des Hernies à Macé ", in Delrieu F., Deslosges J. (dir.) et Quevillon S. (coll.),
ArchéOrne, 250 ans d'archéologie dans l'Orne, catalogue d'exposition, Service régional de l'Archéologie, DRAC de BasseNormandie, Cabourg : éditions Cahiers du Temps, p. 108-109.

LeClerc G., 2008 - "Le sanctuaire gallo-romain de Macé (Orne) ", in L'Archéologue - Archéologie Nouvelle, rubrique "Reportage ", n 94, p. 32-34.

Leclerc G. et Paez-Rezende L., 20 i I - "Présentation des apports scientifiques par thème : Le cultuel ", in Coulthard N., Bilan de la recherche archéologique en Basse-Normandie 1984-2004. L'Antiquité, vol. II, Groupe antiquité BasseNormandie, ministère de la Culture et de la Communication, Direction des Patrimoines, Sous-direction de l'Archéologie, Mission Archéologie. Caen, p. 112-121.

Le Maнo J., I 994 - « Le fanum de l'abbaye Saint-Georges à SaintMartin-de-Boscherville (Seine-Maritime) ", Haute-Normandie Archéologique, vol. III, p. 75-89.

Le Maho J. et Wazylyszyn N., I998 - Saint-Georges de Boscherville : 2000 ans d'histoire, Association touristique de l'abbaye Romane, GRAPC/ATAR, Rouen, 64 p.

Maes K. et VAn Impe L., I986 - " Begraafplaats uit de ijzertijd en Romeinse vondsten op "de Rietem " te Wijshagen (gem. Meeuwen-Gruitrode) ", Archaeologia Belgica, vol. 2, n 1 , p. 47-56.

Maret C., 2006 - "Hecmanville-A28, sur les cours ", Bilan scientifique 2003 de la région Haute-Normandie, Drac de HauteNormandie, Service régional de l'Archéologie, Rouen, p. 52.

Mitard P.-H. avec la collaboration de Berthier G., Hofmann B., Jobelot N. et les contributions de Peulvast J.-P., Poulain M.-T., Blanc A. et Lorenz C., I 994 - Le sanctuaire galloromain des Vaux-de-la-Celle à Genainville (Val-d'Oise), Guiryen-Vexin : éditions du Centre de recherches archéologiques du Vexin français, $452 \mathrm{p}$.

Monaghan J., I987 - "Découvertes maritimes provenant du bailliage de Guernesey ", SFECAG, Actes du congrès de Caen, 1987, p. 39-43.

Mortreau M. et Adrian Y.-M., 2002 - "Les assemblages céramiques du $\mathrm{II}^{\mathrm{e}}$ et de la première moitié du $\mathrm{III}^{\mathrm{e}}$ siècle en plaine de Caen et dans le Bessin (Calvados) : l'exemple de Saint-Martindes-Entrées et de Fleury-sur-Orne ", SFECAG, Actes du congrès de Bayeux, 2002, p. 111-130.

Musset M., I 947 - "Arpentage antique en Normandie ", Revue archéologique, t. XXVIII, $2^{\mathrm{e}}$ vol., 1947, p. 31-51.

Navarre N., I996 - "Étude de la céramique ", in Petorin N. (dir.), Bretteville-L'Orgueilleuse "La Corneille-Nord" (Calvados), DFS de fouille de sauvetage urgent, SRA de BasseNormandie.

Navarre N., I 997 - "La céramique des Antonins au Bas-Empire en plaine de Caen ", SFECAG, Actes du Congrès du Mans, p. 407-429. 
NAVEAU J. (dir.), I 997 - Recherches sur Jublains (Mayenne) et sur la cité des Diablintes, Documents archéologiques de l'Ouest, Rennes, $364 \mathrm{p}$.

PÉchoux L., 2010 - Les sanctuaires de périphérie urbaine en Gaule romaine, Montagnac : éditions Monique Mergoil, 504 p.

PÉchoux L., 20 I I - "Sanctuaires gallo-romains. Honorer les dieux aux portes des villes ", in Archéologia n 485, Dijon : éditions Faton, p. 28-35.

RABEISEN E., I 994 - "Rites de dépôts en nombre : offrandes du temple d'Alésia et d'autres sanctuaires gallo-romains ", in Goudineau C., Fauduet I. et Coulon G. (dir.), Les sanctuaires de tradition indigène en Gaule romaine. Actes du colloque d'Argentomagus (Argenton-sur-Creuse/Saint-Marcel, Indre), 8, 9 et 10 octobre 1992, Paris : éditions Errance, coll. "Archéologie aujourd'hui ", p. 121-127.

RichaRd C., I 994 - Ensembles clos tibéro-claudiens d'un sanctuaire (Le Gué-de-Sciaux, Antigny, Vienne), in Goudineau C., Fauduet I. et Coulon G. (dir.), Les sanctuaires de tradition indigène en Gaule romaine, Actes du colloque d'Argentomagus (Argenton-sur-Creuse/Saint-Marcel, Indre), 8, 9 et 10 octobre 1992, Paris : éditions Errance, coll. «Archéologie aujourd'hui », p. 115-120.

SCHEID J., 2005a - Quand faire, c'est croire. Les rites sacrificiels des Romains, collection historique dirigée par CoRBIN A. et
Schmitт J.-C., Paris : éditions Flammarion, département Aubier, 352 p.

SCHeID J., 2005b - La religion des Romains, Collection Cursus, série " histoire de l'Antiquité " dirigée par Hartog F., Schmitt-Pantel P. et Scheid J., Paris, Armand Colin, 176 p.

Simon L., Jardel K. et Mortreau M., 2002 - " Première approche des horizons céramiques de la plaine de Caen (Calvados), de la Conquête à l'époque claudienne ", SFECAG, Actes du congrès de Bayeux, 2002, p. 11-50.

Symonds R.P., I 992 - Rhenish Wares. Fine dark coloured pottery from Gaul and Germany, Oxford : University Commitee for Archeology, Monograph n ${ }^{\circ}$ 23, $121 \mathrm{p}$.

Van Andringa W., 2002 - La religion en Gaule romaine. Piété et politique (Ier-IIIe siècle apr. J.-C.) Paris : éditions Errance, coll. "Les Hespérides », 336 p.

Weber G., I 994 - "Les sanctuaires de tradition indigène en Allemagne romaine ", in Goudineau C., Fauduet I. et Coulon G. (dir.), Les sanctuaires de tradition indigène en Gaule romaine, Actes du colloque d'Argentomagus (Argenton-surCreuse/Saint-Marcel, Indre), 8, 9 et 10 octobre 1992, Paris : éditions Errance, coll. "Archéologie aujourd'hui ", p. 17-23.

Woimant G.-P., I985 - "Le sanctuaire antique d'Estrées-SaintDenis (Oise). Campagnes de fouilles 1984 et 1985 ", Revue archéologique de Picardie, 3/4, p. 139-142.

Zusammenfassung: Das gallo-römische Heiligtum von „La Pièce des Côtelets“ bei Saint-Martin-des-Entrées (Calvados) - Das Heiligtum „La Pièce des Côtelets" bei Saint-Martin-des-Entrées liegt etwa 4,5 km von Bayeux entfernt, dem antiken Augustodurum, Hauptort der Baiokassen. Ein Peribolos von rund $4500 \mathrm{~m}^{2}$, unterteilt und begrenzt durch große Gräben, umschließt einen Umgangstempel mit zentraler cella, eine aedicula sowie ein großes Gebäude mit Holzfachwerkkonstruktion. Dieser Kultbezirk fügt sich in eine dichte und rechteckig angelegte Flureinteilung ein. Er gehörte zweifellos zu einer ländlichen Ansiedlung, deren Zentrum bisher nicht erfasst wurde. Das Heiligtum wurde von zahlreichen Deponierungen von Kultobjekten begleitet; dabei handelt es sich überwiegend um Keramikfunde und Tierknochen, niedergelegt in den Gräben oder in Gruben. An ihrer Interpretation als kultische Niederlegungen oder Votivgaben besteht kein Zweifel. Das keramische Fundgut zeigt dagegen im Vergleich zu den Fundensembles aus den ländlichen Siedlungen der Region keine bemerkenswerten Unterschiede. Erbaut um die Mitte des 1. Jh. n. Ch. wird der Tempelbezirk am Anfang des 2. nachchristlichen Jahrhunderts vergrößert, einer Periode, die den Zenit seiner Nutzung kennzeichnet, bevor die Anlage dann am Ende des 2. Jh. n. Ch. aufgelassen wird.

Resumen: El santuario galo-romano de "La Pièce des Côtelets" en Saint-Martin-des-Entrées (Calvados) - A unos 4,5 km de Bayeux, antigua capital de la ciudad de Baïocasses, el santuario de "La Pièce des Côtelets" en Saint-Martin-des-Entrées, incluye, en el centro de un períbolo de 4500 metros cuadrados compartimentado y limitado por medio de zanjas anchas, un templo con galería y cella central, un quiosco y un gran edificio de estructura de madera. Este conjunto religioso está integrado en una trama con mallas densas y probablemente asociado a un edificio rural cuyo centro todavía no fue encontrado. Viene con muchos depósitos de mobiliario - cerámica y restos de fauna - recolectados en zanjas o pozos, cuyo carácter ritual o votivo no cabe duda alguna. Sin embargo, el tipo de la cerámica no muestra una gran originalidad en comparación con los corpus de los sitios de hábitats regionales. Construido a mediados del primer siglo de nuestra era, el santuario crece en el siglo II., periodo que marca el apogeo de su funcionamiento hasta el final del siglo II, lo que corresponde al periodo de su abandono.

Schlüsselwörter: Heiligtum, Peribolos, Tempel, Keramik, Kultdepot, Flureinteilung.

Palabras clave: santuario, períbolo, templo, cerámica, depósito cultual, trama. 